Sérgio Eduardo Alves de Paula

\title{
Estudo do Ganho de Energia Elétrica em Painéis Fotovoltaicos usando Rastreamento Solar Baseado em Sistemas Embarcados
}

São Paulo

2015 
Sérgio Eduardo Alves de Paula

\section{Estudo do Ganho de Energia Elétrica em Painéis Fotovoltaicos usando Rastreamento Solar Baseado em Sistemas Embarcados}

Dissertação apresentada à Escola Politécnica da Universidade de São Paulo para a obtenção do título de Mestre em Engenharia Elétrica

São Paulo 2015 
Sérgio Eduardo Alves de Paula

\section{Estudo do Ganho de Energia Elétrica em Painéis Fotovoltaicos usando Rastreamento Solar Baseado em Sistemas Embarcados}

Dissertação apresentada à Escola Politécnica da Universidade de São Paulo para a obtenção do título de Mestre em Engenharia Elétrica

Área de Concentração:

Microeletrônica

Orientador: Prof. Dr. Roberto Koji Onmori

São Paulo

2015 
Este exemplar foi revisado e corrigido em relação à versão original, sob

responsabilidade única do autor e com a anuência de seu orientador.

São Paulo de de

Assinatura do autor:

Assinatura do orientador:

Catalogação-na-publicação

de Paula, Sérgio Eduardo Alves

Estudo do Ganho de Energia Elétrica em Painéis Fotovoltaicos Usando Rastreamento Solar Baseado em Sistemas Embarcados / S. E. A. de Paula -versão corr. -- São Paulo, 2015.

$84 \mathrm{p}$.

Dissertação (Mestrado) - Escola Politécnica da Universidade de São Paulo. Departamento de Engenharia de Sistemas Eletrônicos.

1.Energia elétrica 2.Sistemas embutidos 3.Painéis fotovoltaicos 4.Rastreamento solar I.Universidade de São Paulo. Escola Politécnica. Departamento de Engenharia de Sistemas Eletrônicos II.t. 
Dedico este trabalho à minha esposa Carolina Ós e aos meus pais Conceição e João Alves de Paula 


\section{Agradecimentos}

Ao professor Roberto Koji Onmori, pela orientação e apoio durante todo o processo de realização do Mestrado.

Aos meus pais Conceição e João Alves de Paula, pelo apoio e estímulo à realização do Mestrado e aos quais devo todos os sucessos que atingi em minha carreira.

À minha noiva Carolina Ós, pela paciência e apoio transmitido durante a realização deste trabalho.

Ao amigo Peter Igor Volf, pela ajuda com o projeto e confecção da estrutura mecânica para o painel solar.

Ao amigo e colega de trabalho Jonny Romeiro Doin, pelas oportunidades de evolução na carreira e pelas intensas discussões de engenharia, sobre este trabalho e muitos outros.

Ao professor Marcelo KnörichZuffo, pelo incentivo à realização deste trabalho e valiosas sugestões.

À empresa Micropress, e ao gerente Romário Santos pela confecção das placas de circuito impresso.

Aos meus colegas e demais familiares, pela compreensão nos momentos em que estive ausente, e a todos os demais que colaboraram na execução deste trabalho. 
"É muito melhor lançar-se em busca de conquistas grandiosas, mesmo expondo-se ao fracasso, do que alinhar-se com os pobres de espírito, que nem gozam muito nem sofrem muito, porque vivem numa penumbra cinzenta, onde não conhecem nem vitória, nem derrota."

(Theodore Roosevelt) 


\section{Resumo}

A geração de energia solar fotovoltaica tem crescido anualmente em utilização. Com o aumento dos custos de geração de energia elétrica, fontes renováveis de energia como essa crescem em interesse, até mesmo em aplicações residenciais de microgeração. Este trabalho apresenta o projeto, construção e ensaios de um rastreador solar autônomo, com controle e aquisição de dados de sensoriamento baseado em sistemas embarcados totalmente projetados e produzidos no país, com o objetivo de se aumentar o ganho de energia elétrica gerada a partir de painéis solares de mercado. $O$ projeto do firmware de controle e os algoritmos utilizados foram adaptados continuamente até se atingir os melhores resultados. Foi utilizado um painel solar comum de mercado para realizar os testes, e as placas de circuito impresso projetadas foram confeccionadas localmente. A tomada de dados em diferentes ensaios mostrou que o rastreamento solar de fato aumentou o ganho de energia elétrica com um painel solar comum de mercado, mesmo com alguns problemas a serem corrigidos em uma próxima pesquisa. Assim, a pesquisa realizada confirmou o ganho de energia elétrica para o painel solar escolhido.

Palavras chave: Módulos Fotovoltaicos. Sistemas Embarcados. Rastreamento Solar. Servomotor. Energia Solar. Caracterização. Painéis Solares. 


\begin{abstract}
Photovoltaic solar generators have grown annually in use. With the increase in electricity generation costs, renewable sources of energy like that grow in interest, even in residential microgeneration applications. This work presents the design, construction and testing of a standalone solar tracker, with control and acquisition of sensors data based on embedded systems totally designed and produced in the country, aiming to increase the power generated from retail solar panels. The firmware design and used algorithms have been continuously adapted to achieve the best results. It was used a standard solar panel to perform the tests, and the designed printed circuit boards were manufactured locally. The data taken in different tests showed that the solar tracking actually increased the power generated with a standard solar panel, even with some problems in the design that have to be corrected in a future implementation. So the project was validated and can be used, including microgeneration in ordinary houses.
\end{abstract}

Keywords: Photovoltaic Modules. Embedded Systems. Solar tracking. Servomotor. Solar energy. Characterization. Solar Panels. 


\section{Lista de Figuras}

FIGURA 1 - GRÁFICO DE RADIAÇÃO SOLAR EM FUNÇÃO DO COMPRIMENTO DE ONDA PARA RADIAÇÃO

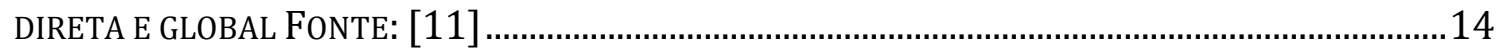

FIGURA 2 - CÉLULA SOLAR FOTOVOLTAICA CONECTADA A UMA CARGA..................................................18

FIGURA 3 - CIRCUITO EQUIVALENTE SIMPLIFICADO DA CÉLULA SOLAR ....................................................19

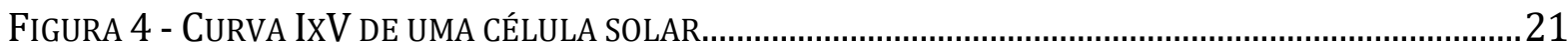

FIGURA 5 - ILUSTRAÇÃO DE UM SISTEMA DE GERAÇÃO FOTOVOLTAICA DE ENERGIA ELÉTRICA ...............23

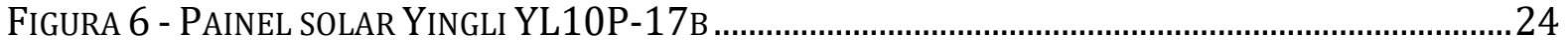

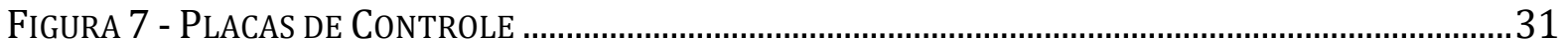

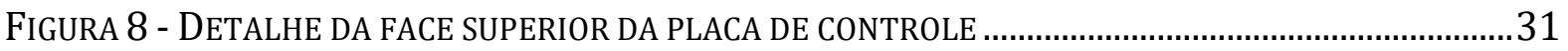

FIGURA 9 - DETALHE DA FACE INFERIOR DA PLACA DE CONTROLE ............................................................. 32

FIGURA 10 - CIRCUITO DE CONDICIONAMENTO DE SINAL DO FOTODIODO …….........................................36

FIGURA 11 - CIRCUITO DE CONDICIONAMENTO DE SINAL DE CORRENTE DA CÉLULA SOLAR......................37

FiguRA 12 - CIRCUITO DE CONDICIONAMENTO DE SINAL DE TENSÃO DA CÉLULA SOLAR ...........................38

FIGURA 13 - DETALHE DA FACE SUPERIOR DA PLACA DE SENSORIAMENTO...............................................3

FIGURA 14 - DETALHE DA FACE INFERIOR DA PLACA DE SENSORIAMENTO ….........................................

FIGURA 15 - SENSIBILIDADE ESPECTRAL RELATIVA X COMPRIMENTO DE ONDA PARA O BPW24R .......41

FIGURA 16 - SENSIBILIDADE À RADIAÇÃO X DESLOCAMENTO ANGULAR PARA o BPW24R .....................41

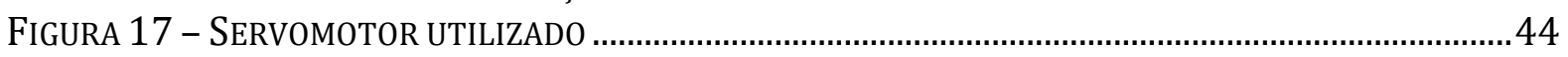

FIGURA 18 - PROJETO MECÂNICO DO SUPORTE PARA O PAINEL SOLAR (1) ...............................................46

FIGURA 19 - PROJETO MECÂNICO DO SUPORTE PARA O PAINEL SOLAR (2) ...............................................46

FIGURA 20 - ESTRUTURA SENDO MONTADA PARA RECEBER O PAINEL SOLAR (1) .....................................47

FIGURA 21 - ESTRUTURA SENDO MONTADA PARA RECEBER O PAINEL SOLAR (2) ....................................48

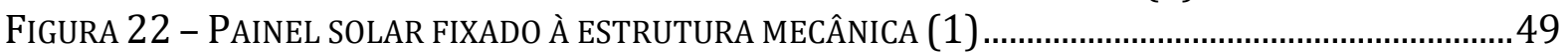

FIGURA 23 - PAINEL SOLAR FIXADO À ESTRUTURA MECÂNICA (2) ……................................................50

FIGURA 24 - FLUXOGRAMA DO ALGORITMO UTILIZADO ......................................................................

FIGURA 25 - GRÁFICO DE EFICIÊNCIA E POTÊNCIA OBTIDOS EM CADA HORA DO DIA 29/11/2014 .....65

FIGURA 26 - GRÁFICO DE EFICIÊNCIA E POTÊNCIA OBTIDOS EM CADA HORA DO DIA 31/12/2014 ......67

FIGURA 27 - GRÁFICO DE EFICIÊNCIA E POTÊNCIA OBTIDOS EM CADA HORA DO DIA 30/01/2015 ......69

FIGURA 28 - GRÁFICO DE EFICIÊNCIA E POTÊNCIA OBTIDOS EM CADA HORA DO DIA 31/01/2015 ......70 


\section{Lista de Tabelas}

TABELA 1 - CARACTERÍSTICAS DO PAINEL SOLAR YL10P-17B EM STC ...................................................24

TABELA 2 - RESULTADOS PARA O DIA 29/11/2014

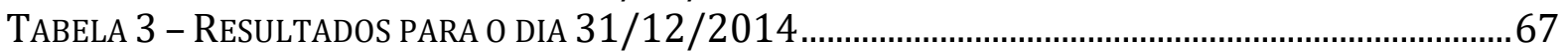

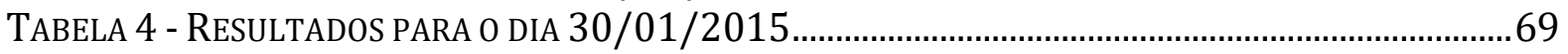

TABELA 5 - RESULTADOS PARA O DIA 31/01/2015 ……................................................................ 70 


\section{Sumário}

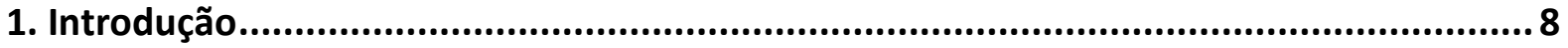

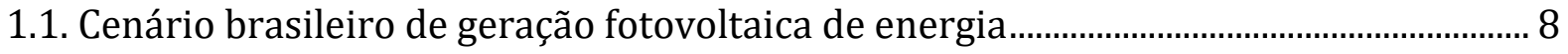

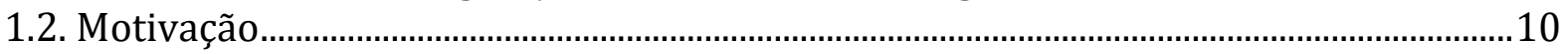

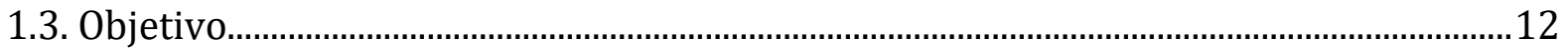

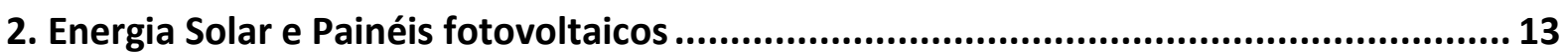

2.1. Painel Solar Utilizado ......................................................................................................... 23

2.2. Diferencial da Pesquisa..................................................................................................... 25

3. Descrição do experimento ........................................................................................ 27

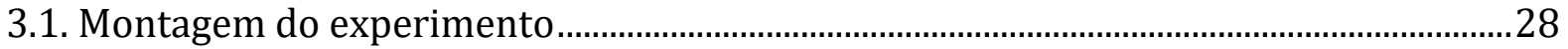

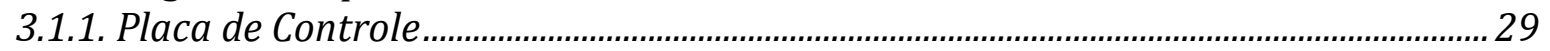

3.1.2. Placa de Sensores...................................................................................................................... 33

3.1.3. Servomotor ......................................................................................................................... 43

3.1.4. Suporte Mecânico para o Painel Solar ............................................................................... 45

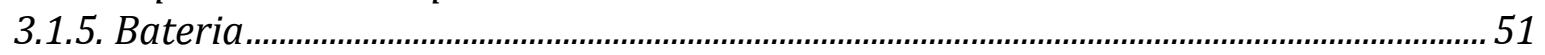

3.1.6. Diagrama de Distribuição do Sistema ...........................................................................51

3.2. Variantes do Experimento.............................................................................................52

3.3. Indicadores a Serem Medidos..........................................................................................53

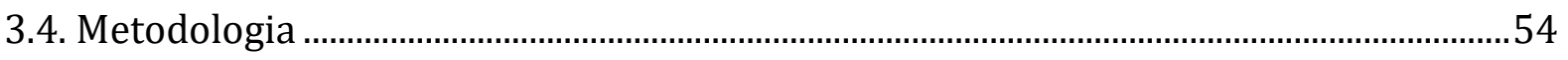

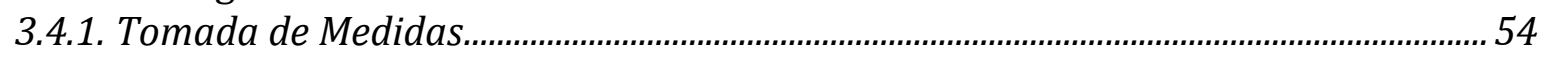

3.4.2. Algoritmos .................................................................................................................. 56

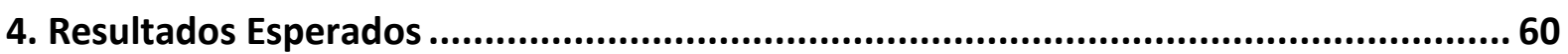

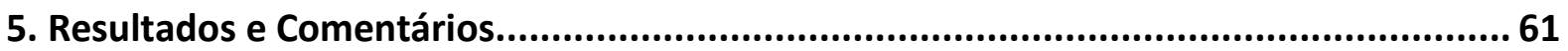

5.1. Medidas Obtidas...........................................................................................................62

5.1.1. Dia 29/11/2014 - dia nublado e sem chuva.................................................................6 63

5.1.2. Dia 31/12/2014 - ensolarado, pouca cobertura de nuvens .........................................65

5.1.3. Dia 30/01/2015 - cobertura parcial de nuvens ............................................................... 68

5.1.4. Dia 31/01/2015 - cobertura parcial de nuvens, sem rastreamento............................69

6. Discussão e Conclusões............................................................................................... 71

7. Previsão de continuação da pesquisa ......................................................................... 73

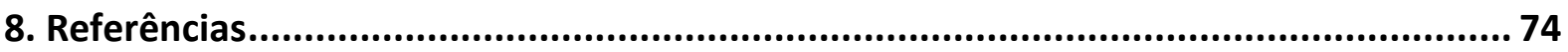

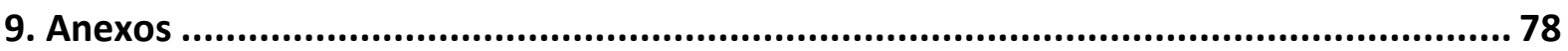

9.1. Anexo 1 - Circuito principal da placa controladora ……………………………………....78

9.1.1. Camada Top da placa de circuito impresso …………..................................................... 79

9.1.2. Camada Bottom da placa de circuito impresso ............................................................ 80

9.1.3. Camada VCC da placa de circuito impresso .................................................................. 81

9.1.4. Camada GND da placa de circuito impresso ................................................................. 82

9.2. Anexo 2 - Circuito da placa de sensores...............................................................................83

9.3. Anexo 3 - Diagrama de distribuição do sistema...................................................................84 


\section{Introdução}

1.1. Cenário brasileiro de geração fotovoltaica de energia

Atualmente, o Brasil apresenta alguns projetos de aproveitamento da energia solar por sistemas fotovoltaicos, atendendo comunidades rurais e isoladas da rede de energia elétrica, apoiando o desenvolvimento regional. Alguns desses projetos recebem o suporte de organismos internacionais, como a Agência Alemã de Cooperação Técnica (GTZ) e o Laboratório de Energia Renovável dos Estados Unidos (NREL). Esses projetos estão focados principalmente em bombeamento de água para abastecimento doméstico, irrigação e piscicultura; iluminação pública; sistemas de uso coletivo (trazer energia elétrica para escolas, postos de saúde, etc.); e para uso domiciliar.

Contudo, o aproveitamento da radiação solar disponível no país é bastante baixo. Apenas para comparação, atualmente o país líder em aplicação da geração fotovoltaica é a Alemanha, sendo que sua radiação global incidente no plano horizontal é de $1200 \mathrm{kWh} / \mathrm{m}^{2} /$ ano no máximo, em suas regiões com mais radiação solar; já o Brasil possui uma radiação global incidente no plano horizontal de $1640 \mathrm{kWh} / \mathrm{m}^{2} / a n o$ no mínimo em suas regiões com menos radiação solar, além de ser muito mais vasto territorialmente. Assim, observase um grande potencial de geração de energia solar no Brasil, com áreas que 
excedem $2200 \mathrm{kWh} / \mathrm{m}^{2} /$ ano de radiação global, porém ainda timidamente aproveitado.

Pode-se dizer que a falta de incentivo para a adoção em maior escala de energia elétrica proveniente da energia solar no Brasil se deve ao fato de grande parte da energia gerada no país ser de origem hidrelétrica, também renovável, em comparação com países desenvolvidos que não tem alternativa senão utilizar combustíveis fósseis para obter energia. Além disso, o custo da energia solar tem sido historicamente mais alto do que se obtém atualmente no país com hidroeletricidade, o que acaba por reduzir o interesse por esse tipo de geração. Contudo, com o aumento anual da tarifa residencial energética no país e o desenvolvimento da tecnologia fotovoltaica, uma paridade poderia ser alcançada entre o custo das duas fontes de energia, favorecendo assim a sua maior adoção [16]. 


\subsection{Motivação}

Atualmente, o cenário de produção e consumo de energia elétrica no planeta aponta para uma demanda crescente por esse recurso, ao passo que o mesmo é produzido em sua grande maioria a partir de fontes não-renováveis e poluentes, como carvão, petróleo e gás natural. Assim, um dos maiores desafios da sociedade corrente se dá pela busca por novas fontes de energia, renováveis e limpas.

A geração de energia a partir de painéis solares fotovoltaicos se posiciona como uma das soluções possíveis desse desafio. Sua geração não polui e sua fonte é inesgotável, uma vez que tem origem em reações de fusão de átomos dentro do sol. Para se ter uma ideia, a cobertura de $0.16 \%$ da superfície terrestre com painéis solares fotovoltaicos de $10 \%$ de eficiência teria a capacidade de produzir 20 TW de potência elétrica [4].

Os principais problemas para a utilização em larga escala de painéis solares fotovoltaicos são sua relativa baixa eficiência de conversão de energia e seu alto custo de implantação e manutenção, se comparados com as mesmas características dos processos de geração energética mais utilizada atualmente.

Assim, justifica-se o estudo de formas de solucionar esses problemas de modo a viabilizar cada vez mais a utilização desse tipo de geração de energia. Diversas pesquisas já estão em andamento há muitos anos para aumentar a eficiência dos painéis, melhorando-se o processo de fabricação com 
semicondutores. Este trabalho, contudo, estarão focados na utilização de painéis solares convencionais já presentes no mercado, cujo custo é acessível, propondo formas de aumentar sua eficiência nominal.

Uma forma introdutória proposta seria viabilizar seu uso inicialmente pelas pessoas em suas casas, amortizando assim parte de seu consumo de energia elétrica. Para isso, o custo final da solução precisa ser viável, bem como o sistema deve precisar do menor nível de interação possível com o usuário, favorecendo sua popularização. 


\subsection{Objetivo}

O objetivo deste trabalho é estudar diferentes formas de rastreamento solar em uma mesma estrutura montada, variando-se os algoritmos de rastreamento e parâmetros de utilização do mesmo para atingir uma configuração ótima do experimento, de forma a aumentar a eficiência de conversão energética de células solares convencionais. Essa configuração ótima poderá ser proposta para utilização de células solares convencionais pela população como alternativa energética limpa e de custo viável, se valendo do aumento de eficiência atingido. 


\section{Energia Solar e Painéis fotovoltaicos}

A radiação solar existe como produto do aquecimento da camada do Sol chamada de cromosfera, devido à fusão de átomos no interior do corpo celeste. Essa radiação é emitida com uma larga faixa de espectro, variando de 200nm a 50000nm. Se aproximando da Terra, se observa uma radiação média de $1367 \mathrm{~W} / \mathrm{m}^{2}$, sendo que aproximadamente $75 \%$ desse valor passa para dentro da atmosfera sem ser dispersado ou absorvido em um dia de céu limpo. Assim, aproximadamente $1000 \mathrm{~W} / \mathrm{m}^{2}$ de radiação solar atinge a superfície da Terra, o que é chamado de radiação normal direta. Uma parte da luz solar que foi dispersa acaba também por atingir a superfície terrestre, sendo que essa parcela de radiação é chamada de radiação difusa. Existe ainda um terceiro tipo de radiação sobre um dado observador que é resultado de reflexão no solo e posterior dispersão em direção ao observador. Esta última pode ter seu efeito pronunciado em locais com o solo coberto por neve, por exemplo. A soma de todas as formas de radiação citadas sobre a superfície da terra é chamada de radiação global. Sabe-se que para os comprimentos de onda visíveis, entre 380 a 780 nm, a radiação solar tem uma componente difusa bastante pronunciada, aumentando a radiação global em até $40 \%$ em relação à radiação normal direta, como se pode observar na Figura 1 [11]. 


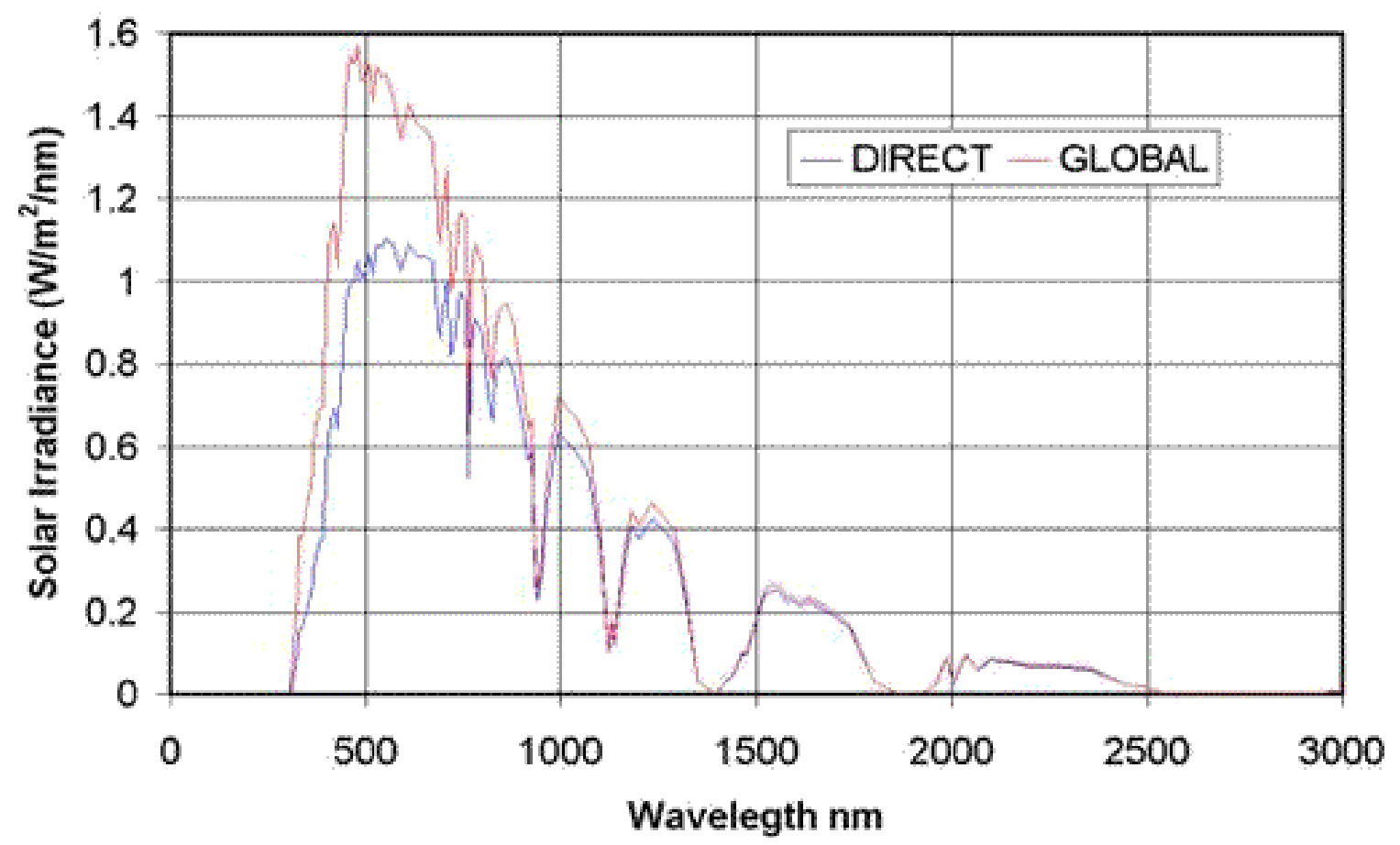

Figura 1 - Gráfico de radiação solar em função do comprimento de onda para radiação direta e global Fonte: [11]

Assim, com a entrada dos raios solares na atmosfera, os mesmos são atenuados pela dispersão e absorção, principalmente ao ozônio, vapor de água, ar seco e poeira. Quanto maior for a distância percorrida pelos raios solares na atmosfera, maior será esse efeito de atenuação. Por isso, é comum se caracterizar o caminho pelo qual a luz solar terá de percorrer até o observador em comparação com o caminho que a luz percorreria se o sol estivesse verticalmente acima do observador, no Zênite. Essa relação é chamada de coeficiente de massa de ar, ou AM (de Air Mass Coefficient em inglês). 
Esse coeficiente acima citado possui alguns casos de uso padrão, como descrito a seguir:

- AM0: os raios solares não passaram pela atmosfera, como quando se usam painéis solares em satélites de comunicação.

- AM1: quando o Sol está exatamente acima do observador, no ângulo de Zênite, e seus raios solares atingem o observador ao nível do mar. Também referido como "uma atmosfera" .

- AM1.5: os maiores centros populacionais do planeta se localizam em latitudes temperadas, como grande parte da Europa, China, Japão, EUA, etc. Em muitas dessas regiões no verão, ao meio do dia o AM é menor do que 1.5; porém na parte da manhã e da noite, assim como em outras estações do ano, esse AM é maior. Assim, pode-se dizer que 1.5 é um bom padrão para essas regiões do planeta. Esse AM ocorre a um ângulo de Zênite de $48,2^{\circ}$.

- $\mathrm{AM} 2$ a 3: $\mathrm{AM} 2$, a um ângulo Zênite de $60^{\circ}$ e $\mathrm{AM} 3$ a $70^{\circ}$ são em média bons padrões para regiões de maiores latitudes.

- AM38: coeficiente de massa de ar para um ângulo de Zênite horizontal, de $90^{\circ}$.

O coeficiente de massa de ar, em conjunto com outros parâmetros, é utilizado para caracterizar sistemas baseados em energia solar. Essa caracterização é 
feita sob condições de teste padrão, ou STC - do inglês Standard Test Conditions -, cujos parâmetros são radiação a $1000 \mathrm{~W} / \mathrm{m}^{2}$, AM 1.5 e temperatura de painel $25^{\circ} \mathrm{C}$.

Pelo que foi descrito anteriormente, apenas foi abordada a questão de raios solares incidindo sobre uma superfície horizontal. Se o painel solar for inclinado na direção do Sol, a radiação normal direta é aumentada, a difusa é reduzida e uma parcela de reflexão da luz no solo é adicionada, o que pode ser bastante significativa no caso dessa superfície ser de concreto, areia ou coberta de neve. Assim, quanto mais tempo o painel solar estiver virado na direção do Sol, maior será a energia recebida. Além disso, deve-se considerar a latitude do local no qual está instalado o painel solar, inclinando ele de forma otimizada durante as estações. Uma situação ideal de céu limpo e ensolarado durante o ano todo faria com que esse ângulo de inclinação ótimo fosse igual à latitude do local; porém, em locais com radiação difusa pronunciada se beneficiam de um ângulo menor de inclinação, bem como um maior ângulo melhora a recepção de energia solar durante dias de inverno ensolarados [11].

Referindo-se ao processo de conversão de energia, a radiação solar é usada tipicamente para gerar energia elétrica por dois processos distintos: o termelétrico e o fotovoltaico. O primeiro se baseia na transformação de energia luminosa em térmica, para então converter esta última em elétrica; já o segundo se baseia no efeito fotovoltaico dos semicondutores para gerar 
energia elétrica diretamente a partir da luminosa. Este trabalho está focado unicamente neste segundo processo, que será descrito a seguir.

Uma célula solar fotovoltaica é normalmente construída com silício monocristalino, silício policristalino ou arseneto de gálio. Focam-se neste trabalho aquelas células solares feitas de silício monocristalino. Tais células são tipicamente do tipo "n sobre p" ou "p sobre n" , dependendo do tipo de dopagem inicial do silício e a que se faz posteriormente no processo de fabricação. Toma-se como exemplo o modelo " $n$ sobre $p$ ", no qual um wafer de silício monocristalino dopado com boro (silício p) recebe uma difusão de fósforo, o que forma o silício $n$, constituindo assim uma junção $p$ n. O fósforo causa um excesso de elétrons no lado n, bem como o boro causa um excesso de lacunas no lado p, o que origina uma corrente de difusão nas proximidades da junção devido a essa diferença de concentração: elétrons do lado $\mathrm{n}$ migram para $\mathrm{o} \mathrm{p}$ e se recombinam com lacunas majoritárias, bem como lacunas do lado $\mathrm{p}$ migram para o lado $\mathrm{n}$ e se recombinam com elétrons majoritários. Esse processo ocasiona uma depleção de elétrons no lado n da junção e de lacunas no lado p. Com isso, cargas positivas do lado n ficarão descobertas, bom como cargas negativas do lado $p$ também ficarão. Com isso, uma queda de tensão reversa passa a existir na região da junção, na chamada região de depleção. Esse potencial deverá ser vencido para que lacunas cheguem à região $n$ e elétrons cheguem à região $p$ [18]. 
Quando a radiação solar atinge a superfície da célula solar, fótons com energia acima do gap do semicondutor (1,1 eV para o silício) conseguem interagir com elétrons de valência do material e os promovem à banda de condução, criando pares elétron-lacuna. Alguns desses elétrons e lacunas se recombinam, gerando calor; outros conseguem chegar até a junção, sendo que elétrons são acelerados pelo campo reverso para o lado $\mathrm{n}$ e lacunas para o lado p. Se houver uma carga conectada aos eletrodos dessa junção, uma corrente começará a passar, saindo do lado $\mathrm{p}$ (eletrodo positivo), passando pela carga e retornando para o lado $\mathrm{n}$ (eletrodo negativo). Essa corrente gerada é proporcional à radiação solar e à área da célula. A Figura 2 ilustra o efeito descrito.

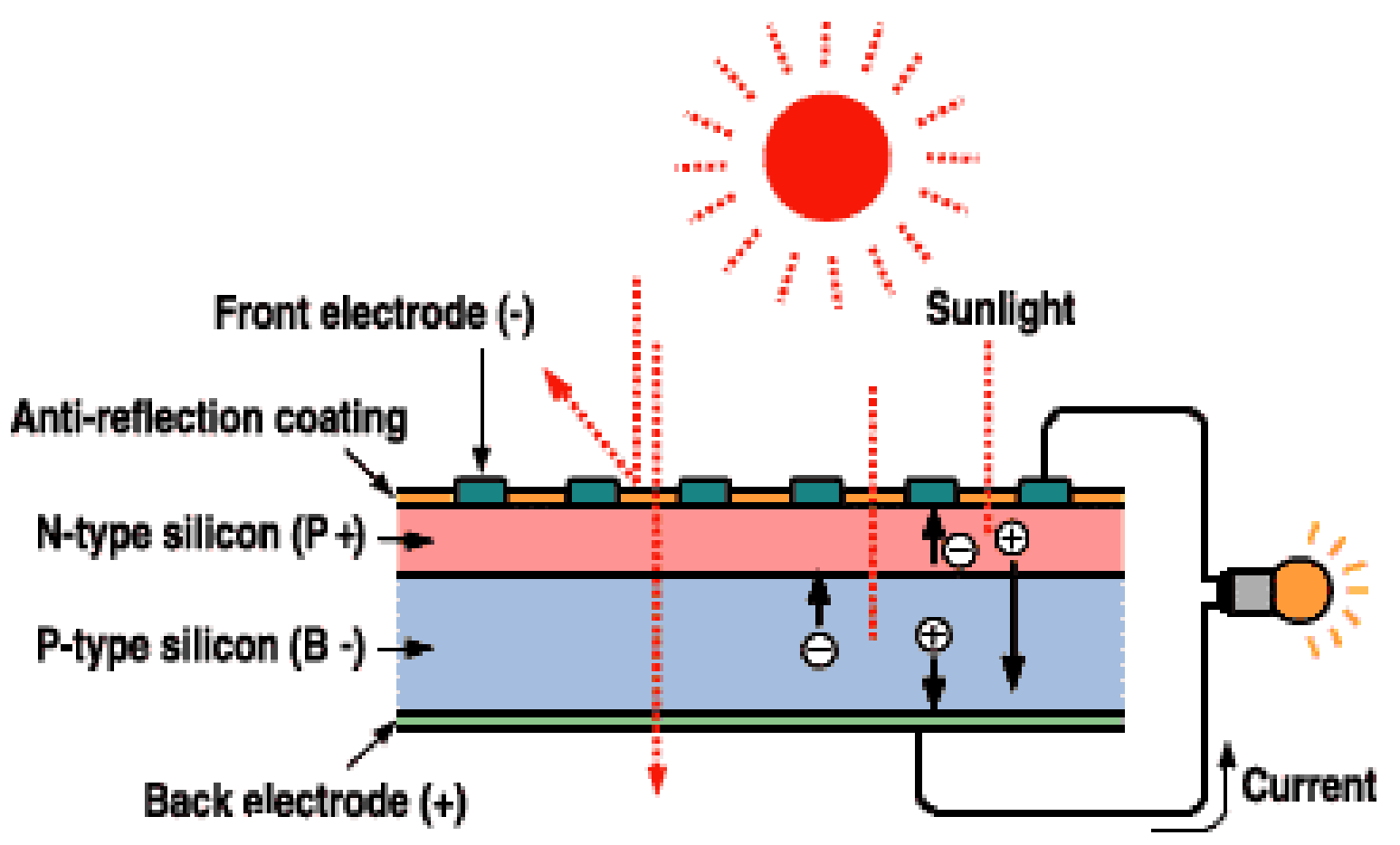

Figura 2 - Célula solar fotovoltaica conectada a uma carga

Fonte: Boureau of Labor Statistics, http://www.bls.gov/green/solar_power/ 
O circuito equivalente da célula solar pode ser visto na Figura 3. Neste circuito, Rs é a resistência em série associada à célula, RL é a resistência da carga, IG é a corrente gerada, IJ é a corrente de deriva da junção e $V$ a tensão de saída.

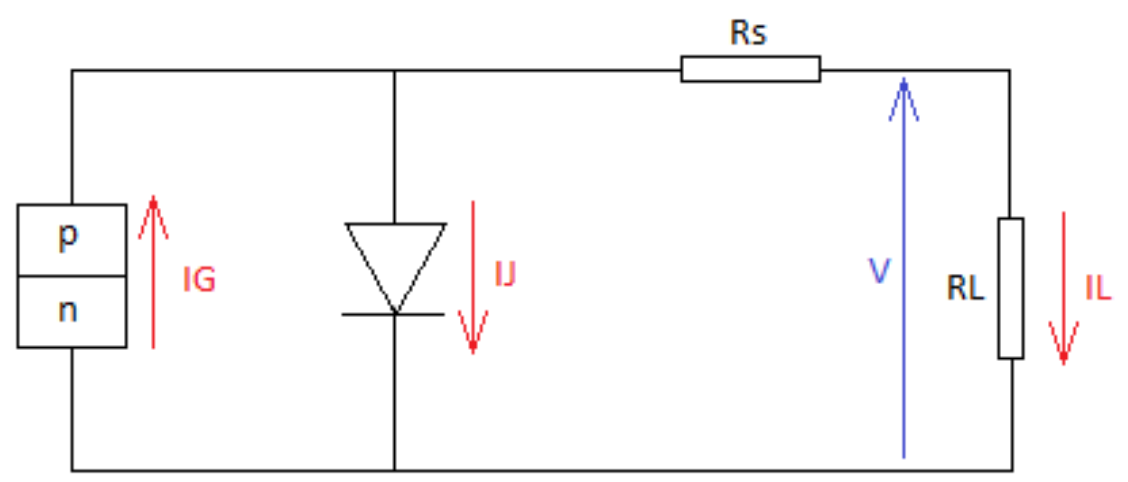

Figura 3 - Circuito equivalente simplificado da célula solar

De posse de dados de resposta espectral da célula solar em função do comprimento de onda da luz incidente, identificado como $P(\lambda)$ e cuja unidade é $A^{*} \mathrm{~cm}^{2} / W$, e da distribuição espectral da radiação incidente, identificado como $\mathrm{G}(\lambda)$ e cuja unidade é $\mathrm{W} / \mathrm{cm}^{2}$, pode-se chegar à corrente gerada:

$I_{G}=\int P(\lambda) \cdot G(\lambda) \cdot d \lambda$

$I_{I}=I_{0} \cdot\left(\exp \left(\frac{q-V+I_{L} \cdot R_{S} J}{A-k \cdot T}\right)-1\right)$ 
Onde:

lo: corrente reversa de saturação de escuro do diodo (A)

q: carga do elétron $(1,6 \mathrm{E}-19 \mathrm{C})$

k: constante de Boltzmann (1,38E-23 J/K)

$\mathrm{T}$ : temperatura absoluta da célula solar, em $\mathrm{K}$

A: constante entre 1 e 2 , dependendo do tipo de célula

V: tensão na carga

Por fim, a corrente da carga é dada por:

$I_{L}=I_{G}-I_{J}$

Com isso, em condição de curto circuito $(V=0)$, IJ se torna muito pequena e pode-se dizer que toda a corrente gerada passa pela carga.

$I_{s c} \cong I_{G}$

Já em condição de circuito aberto (IL=0), tem-se:

$$
V_{o Q}=\frac{A \cdot k \cdot T}{q} \cdot \ln \left(\frac{I_{G}}{I_{\sigma}}+1\right)
$$

Além da corrente de curto-circuito (medida após curto-circuitar os terminais da célula) e da tensão de circuito aberto (medida sem carga), é comum obter 
também os valores de potência máxima da célula (Pmax), bem como os valores de corrente (Imax) e tensão (Vmax) da célula nessa condição.

A Figura 4 é um exemplo de curva IxV de uma célula solar, indicando os pontos notáveis citados.

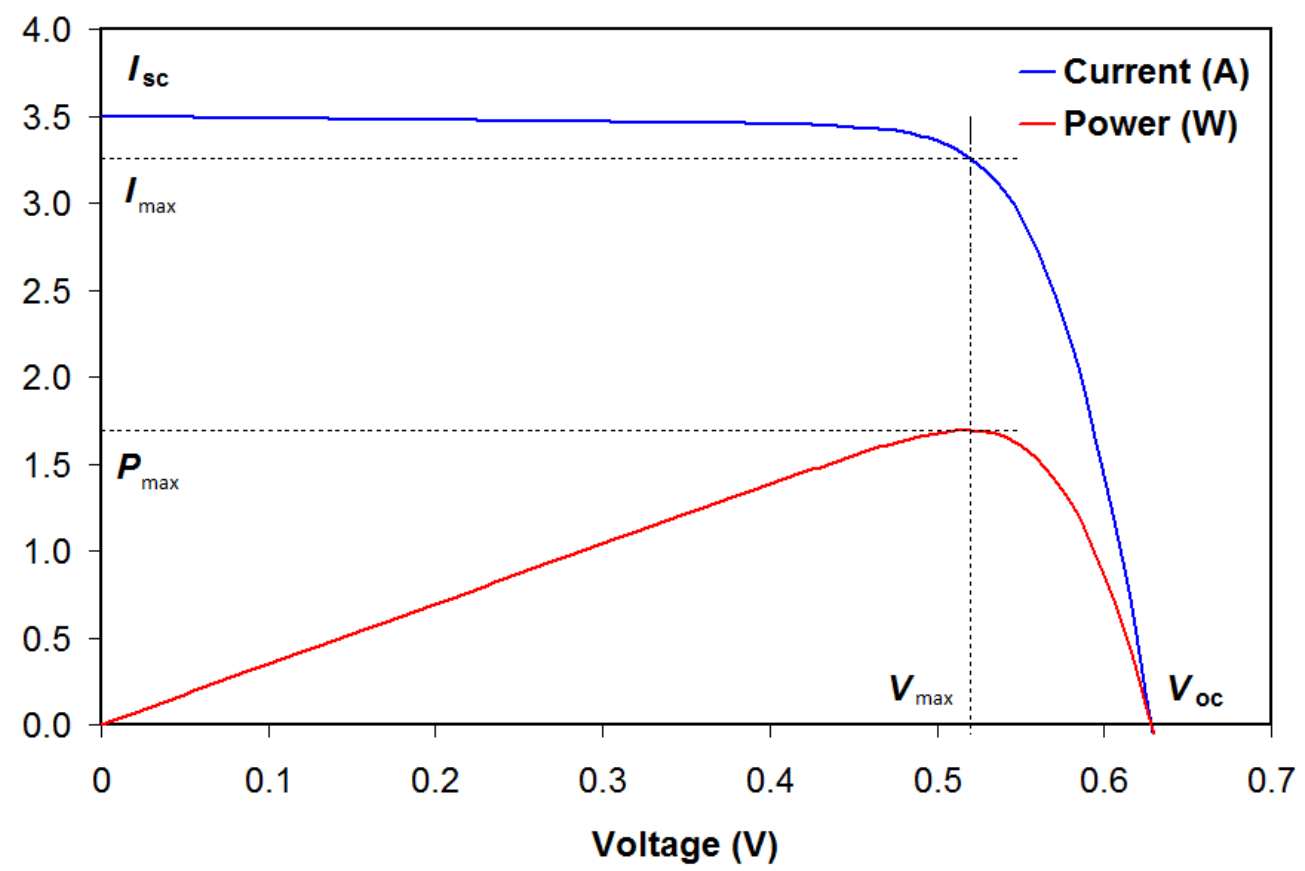

Figura 4 - Curva IxV de uma célula solar

O ponto de máxima potência (Vmax, Imax) é determinado após desenhar o retângulo de maior área dentro da curva IxV em questão.

Por fim, pode-se calcular dois parâmetros importantes para caracterizar a célula solar, de posse dos valores anteriormente citados. Um deles é o fator de preenchimento, do inglês Fill Factor. Ele mede o efeito da qualidade da 
junção e da resistência série da célula na performance de conversão de energia.

$$
F F=\frac{I_{\max } \cdot V_{\max }}{I_{s e} \cdot V_{o c}}=\frac{P_{\max }}{I_{s e} \cdot V_{o c}}
$$

Além disso, pode-se também obter a eficiência de conversão energética, como sendo uma porcentagem da energia gerada em relação à potência luminosa incidente [1]:

$\eta=\frac{P_{\max }}{P_{\text {ined }}}=\frac{F F \cdot I_{s c} \cdot V_{o c}}{\text { Irradiância } \cdot \text { Area }}$

Para montar um painel solar, se conectam várias células solares em uma associação em série - para atingir a tensão desejada para o arranjo final - e, após obter algumas associações séries como essa, conectam-se elas em paralelo para obter a corrente desejada para o arranjo. É comum a utilização de painéis em 12 Vdc ou $24 \mathrm{Vdc}$.

Para se obter o ponto máximo de potência do painel solar, é necessário que a carga conectada ao arranjo seja tal que sua tensão e corrente fiquem o mais próximo possível de Vmax e Imax. Para isso, um controlador de carga externa é comumente usado, sendo instalado entre o painel solar e um banco de baterias para armazenamento. Por fim, se o uso final da energia gerada for para eletrodomésticos, lâmpadas, etc., pode-se usar um inversor para se obter corrente alternada. 


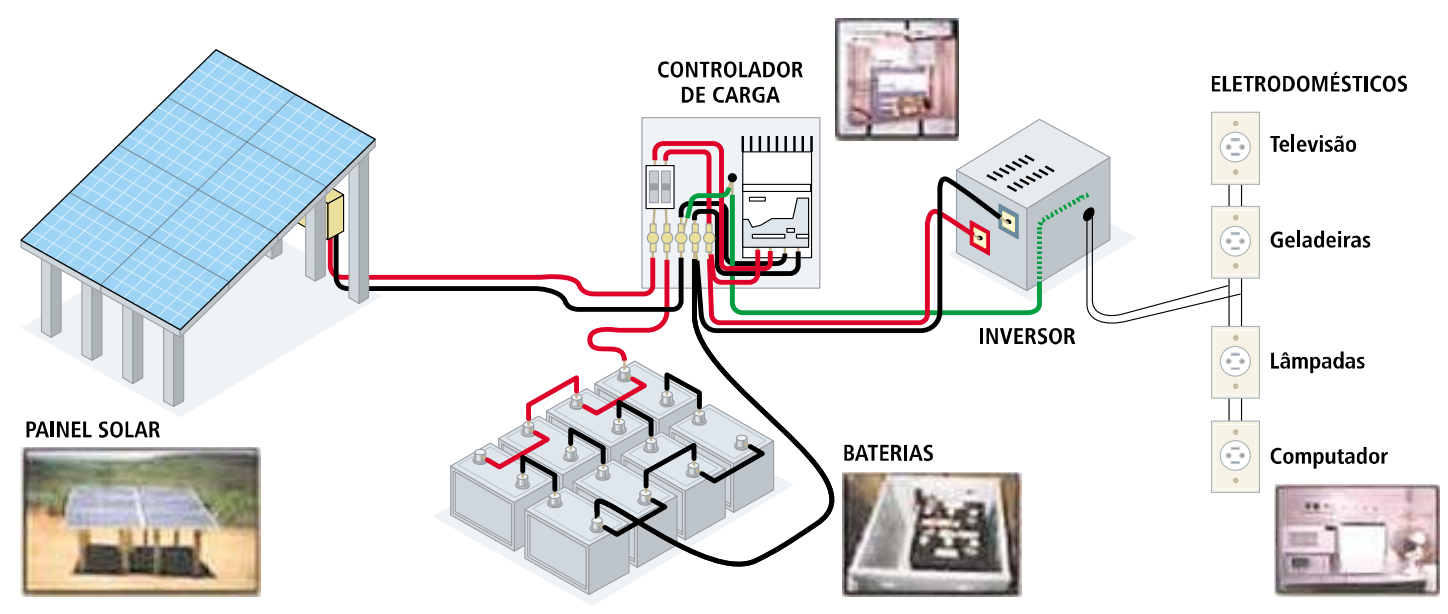

Figura 5 - Ilustração de um sistema de geração fotovoltaica de energia elétrica Fonte: CENTRO DE REFERÊNCIA PARA A ENERGIA SOLAR E EÓLICA SÉRGIO DE SALVO BRITO CRESESB (2000)

\subsection{Painel Solar Utilizado}

Os painéis solares que serão usados neste trabalho devem ser tais que possam ser encontrados com facilidade no mercado, e que possuam um preço acessível, garantindo que sua aplicação não se torne proibitiva - assim como descrito no item 1. Outro fator que foi considerado na escolha é o tamanho e peso do painel para este trabalho, uma vez que para fins de pesquisa não se pretende montar estruturas de dimensões excessivas.

Assim, escolheu-se um painel do fabricante Yingli, modelo YL10P-17b. Este é um painel de $10 \mathrm{~W}$ feito de células solares de silício policristalino, com cobertura de vidro texturizado. Suas dimensões são de 350 por $305 \mathrm{~mm}$ e eficiência nominal de 10 \%. Assim, considera-se que este painel representa de forma adequada o que pode se encontrar no mercado, com um bom 
balanceamento entre custo e eficiência, sem exceder as dimensões prédefinidas para este trabalho.

Na tabela 1 encontram se algumas informações sobre esse painel em STC (Standard Test Conditions, ou condições padrão de teste, o que significa 1000 W/m2 de radiação), bem como uma foto do mesmo.

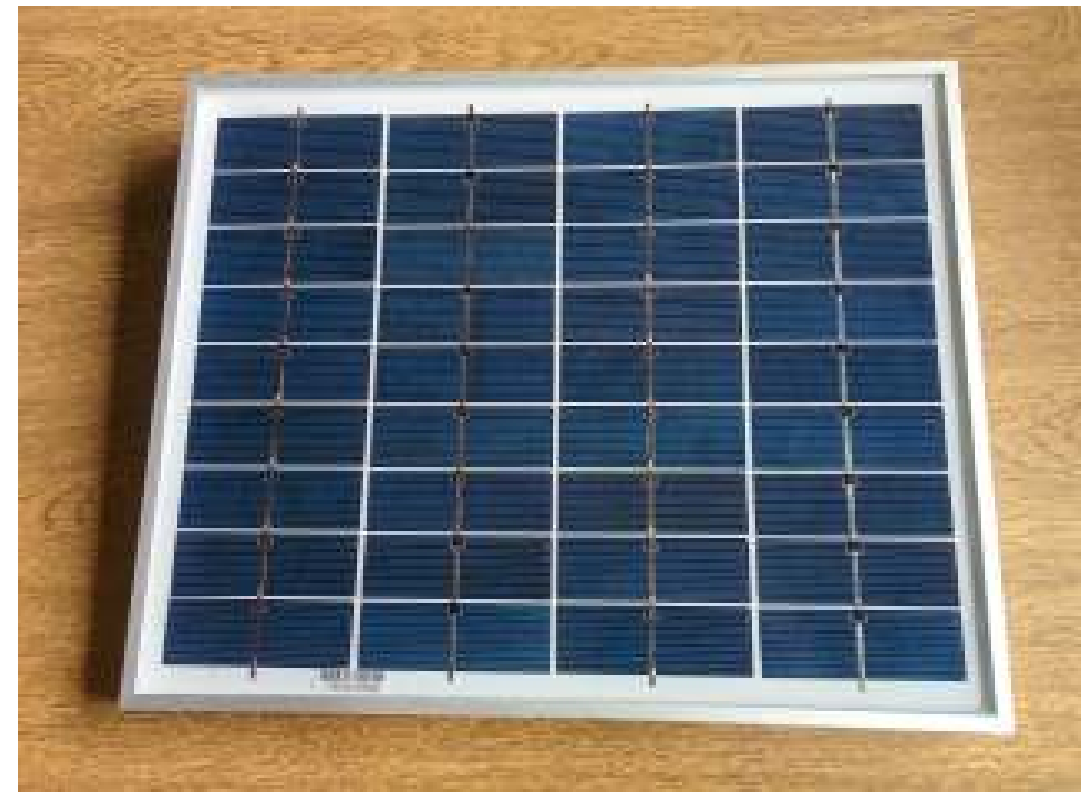

Figura 6 - Painel solar Yingli YL10P-17b

\begin{tabular}{cc}
\hline Corrente de curto circuito (Isc) & $0,62 \mathrm{~A}$ \\
\hline Tensão de circuito aberto (Voc) & $21,2 \mathrm{~V}$ \\
Corrente máxima (Imax) & $0,58 \mathrm{~A}$ \\
Tensão máxima (Vmax) & $17,1 \mathrm{~V}$ \\
Potência máxima (Pmax) & $10 \mathrm{~W}$ \\
\hline
\end{tabular}

Tabela 1 - Características do painel solar YL10P-17b em STC 


\subsection{Diferencial da Pesquisa}

Foi observado na literatura que existem diversas pesquisas que incluem rastreamento solar, dos tipos ativo e passivo. Contudo, essas pesquisas focam, em geral, na geração de modelos teóricos [6] de rastreamento solar e projeção de ganhos de energia e outros efeitos causados pelo rastreamento, sem contudo obter empiricamente os resultados de tal prática. Em outros casos, se alega terem realizado a implementação, porém nenhum detalhe do desenvolvimento do sistema é revelado, apresentando-se apenas os resultados [2]. Por fim, existem diversas pesquisas nas quais muito foco é atribuído ao algoritmo de controle, a estratégia de desenvolvimento do firmware a ser gravado no microcontrolador, porém sem descrever com maiores detalhes a parte de sensoriamento, os circuitos eletrônicos desenvolvidos para tal e a aquisição dos dados [5] [17].

Este trabalho, no entanto, teve como motivação principal o desenvolvimento do próprio sistema de rastreamento, de maneira a evidenciar os principais desafios enfrentados para se obter um ganho substancial de energia elétrica. Além disso, a instrumentação do sistema, implementação do firmware de controle e correlação entre as decisões de projeto e resultados obtidos são outros pontos não abordados na literatura. Por fim, os erros cometidos e problemas encontrados também foram evidenciados, por forma a não serem repetidos em futuras pesquisas que se baseiem nesta. São esses portanto, os pontos que diferenciam esta pesquisa das demais observadas na literatura. 
A principal questão que se objetiva responder seria:

"É possível obter ganho de energia elétrica em painéis convencionais, de baixo custo e eficiência nominal, usando para isso sensores, acionamento e sistema embarcado tradicionais, também de baixo custo, tendo como maior valor agregado a estratégia adotada para rastreamento e as técnicas de desenvolvimento de sistemas embarcados usadas?" . 


\section{Descrição do experimento}

Será montada uma estrutura composta de:

- Painel de células solares convencionais de mercado

- Placa de controle, que realiza o papel de atuação sobre o motor e recebe dados dos sensores, com capacidade de envio desses dados para usuários remotos

- Placas de sensores

- Servo motor, para movimentar a estrutura

- Suporte mecânico que permite a instalação do painel solar e que tenha dois graus de liberdade de rotação, o que poderá ser explorado pelo servo motor

- Bateria para armazenamento da energia convertida e alimentação do sistema de rastreamento solar

Essa estrutura será usada para realizar experimentos de rastreamento solar para tomada de dados do painel de células fotovoltaicas instalado sobre a mesma. 


\subsection{Montagem do experimento}

A estrutura descrita anteriormente será montada fixando-se o painel de células solares sobre o suporte mecânico. Como já observado, esse suporte deve possuir dois graus de liberdade de rotação, o que permitirá rastrear o Sol na direção Leste-Oeste durante o dia, além de corrigir a posição do painel solar em relação à variação latitudinal da posição do Sol durante as estações do ano. O servo motor será acoplado à montagem para que haja a rotação no sentido Leste-Oeste, sendo que um esquema de redução pode ser necessário devido ao peso da estrutura montada.

A placa de controle será fixada na parte traseira do painel, de maneira a se evitar a desnecessária exposição da mesma às intempéries diárias. Essa placa possui uma importância maior no sistema, dado o seu papel de atuação sobre o motor, recepção de dados sensoriais e envio de informações para fora da estrutura.

A estrutura sendo montada será posicionada de forma que o sentido de rotação do painel siga a orientação leste para oeste durante o dia, de forma a se poder rastrear a posição do Sol.

As placas de sensoriamento serão dispostas nas posições leste e oeste do painel solar já posicionado. A razão para isso será exposta mais à frente neste documento. 
A estrutura de montagem pode ser observada no Anexo 3, Diagrama de Distribuição do Sistema, presente ao final deste documento.

\subsubsection{Placa de Controle}

A placa de controle é um sistema embarcado de tempo real desenvolvida com o propósito específico para esta pesquisa. Ela é constituída por:

- Microcontrolador ARM7 de 32 bits, rodando a $72 \mathrm{MHz}$, e que possui 512 kB de ROM e 92 kB de RAM (LPC2387 da NXP)

- 3 interfaces SPI via conector para atuação/controle externo e um barramento i2c via conector para receber o sinal dos sensores no painel

- Alimentação de $24 \mathrm{~V}$ DC, com possibilidade de funcionamento sem falha entre $8 \mathrm{~V}$ e $36 \mathrm{~V} D C$

- Conectividade Ethernet, para transferência de dados em tempo real ou sob demanda via sockets TCP ou UDP sobre IP

- Memória flash serial de 8 MB para armazenamento de dados, configurações e calibrações do sistema/experimento

- Bateria recarregável de $3 \mathrm{~V}$ para manter o relógio do sistema e a memória não volátil do microcontrolador por 1 semana caso o sistema fique sem alimentação 
- Firmware desenvolvido em ANSI C99 e ARM Assembly, com kernel desenvolvido para a aplicação desta pesquisa (sem utilização de RTOS)

Tomou-se a decisão de desenvolver a placa de controle para essa pesquisa após ponderações do que poderia se obter com ela em comparação com o que sistemas prontos de mercado podem oferecer, como Arduino, RaspberryPi, BeagleBoard, BeagleBone, etc. Foi observado que esses últimos são pertinentes à esta pesquisa, muitos deles possuindo já extensões de hardware de sensores com bibliotecas prontas para utilização; contudo, esta pesquisa tem o objetivo de propor uma solução viável de rastreamento solar para aumento de eficiência da conversão para energia elétrica. Sendo assim, o sistema deve não apenas ser capaz de rastrear o sol e adquirir dados de sensores, mas também deve ter o menor consumo possível de energia - uma vez que sua fonte de energia será a bateria que está conectada ao painel solar - , deve ter confiabilidade garantida em ambientes agressivos (altas temperaturas de operação, umidade, chuva, etc.) e sua substituição em caso de falha em uma aplicação real não deve ter um custo proibitivo.

Abaixo se encontram fotos das placas de controle desenvolvidas, montadas e testadas. 


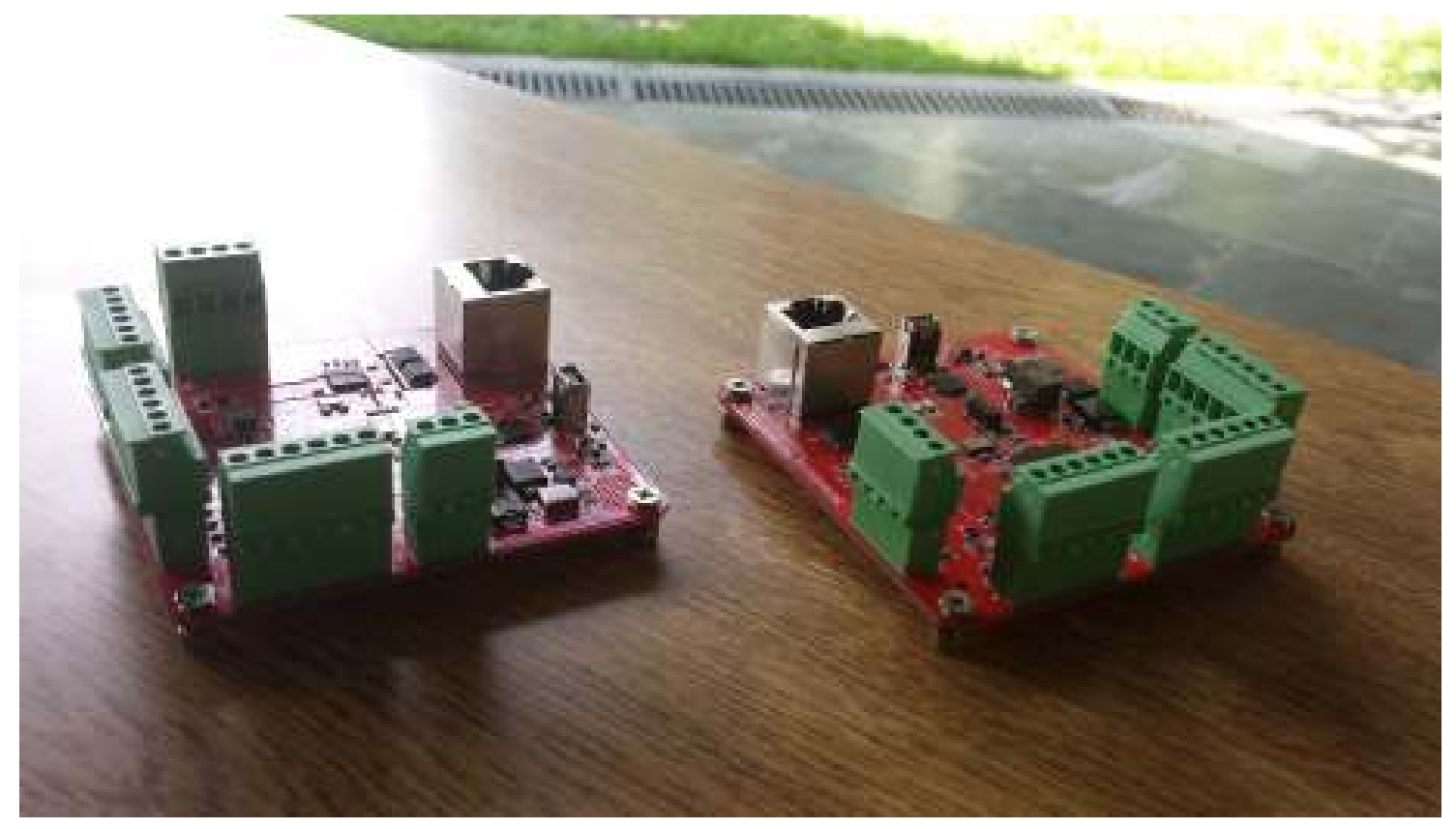

Figura 7 - Placas de Controle

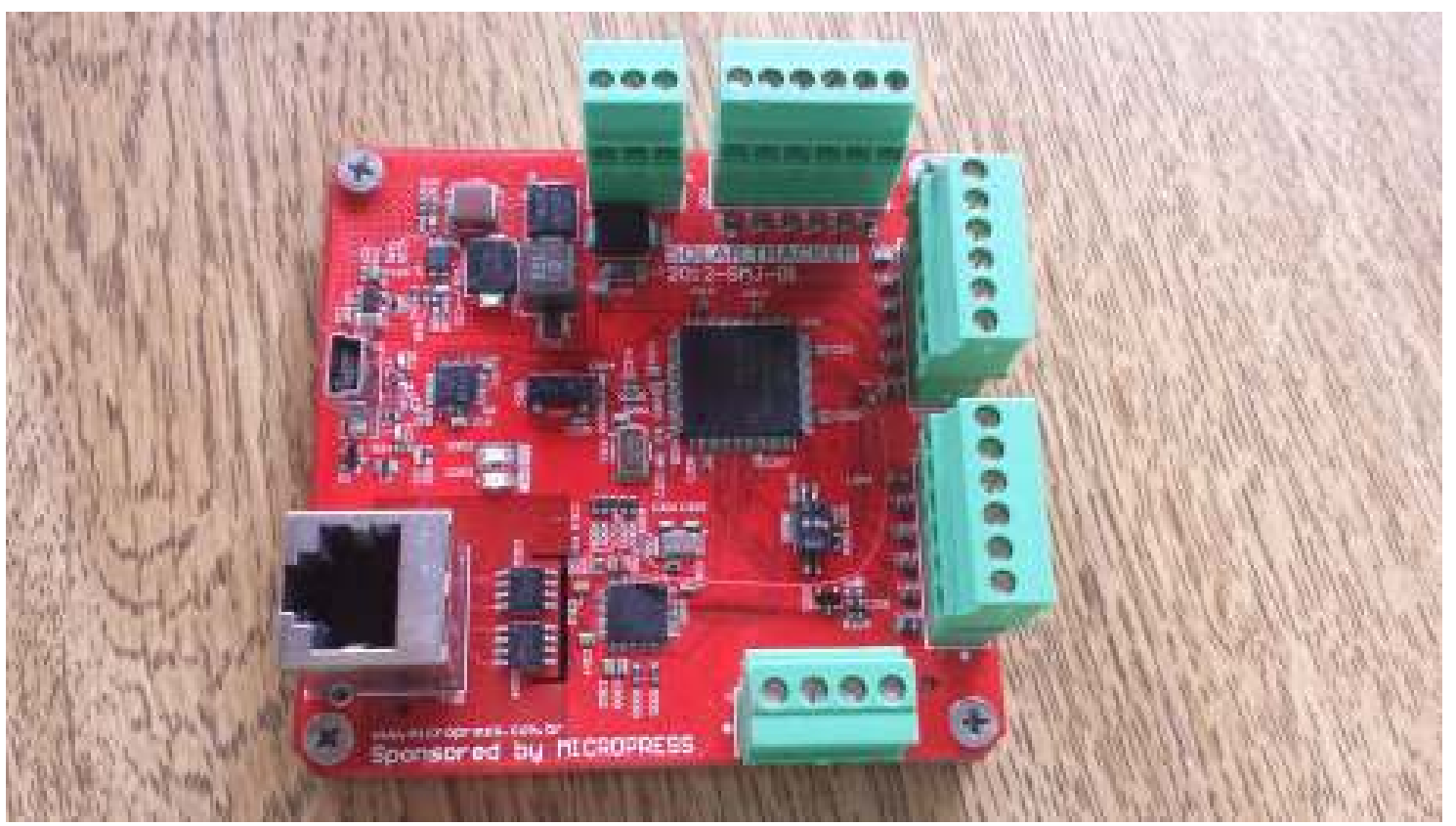

Figura 8 - Detalhe da face superior da placa de controle 


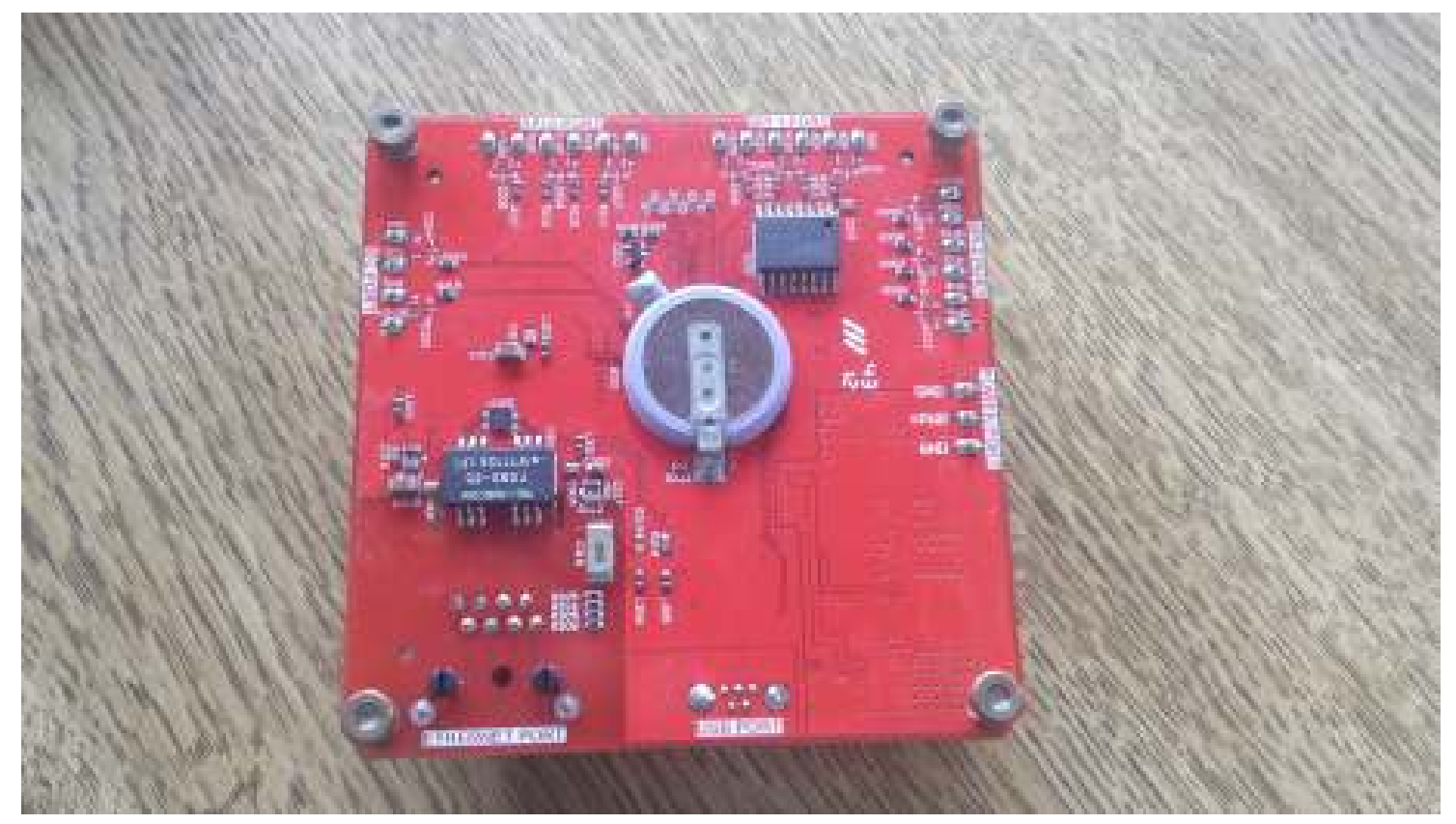

Figura 9 - Detalhe da face inferior da placa de controle

O Anexo 1, ao final deste documento, apresenta o circuito esquemático principal da placa controladora, bem como o circuito impresso em nas 4 camadas da mesma. 


\subsubsection{Placa de Sensores}

A placa de sensores foi desenvolvida separadamente da placa de controle, pois:

- Torna-se necessário distribuir sensores pela superfície do painel solar, podendo inclusive alterar esse posicionamento para atingir os pontos ideais de operação

- Casos de avarias nos sensores podem ser resolvidos trocando apenas a placa de sensoriamento, de menor custo e menor complexidade do que a placa controladora

- Estrategicamente para esta pesquisa, manter a placa controladora mais complexa em um ambiente mais protegido é uma solução considerada melhor

A placa de sensores é composta de:

- 1 sensor que realiza medida de temperatura e umidade, Si7005 da SiliconLabs

- 4 fotodiodos, BPW24R da Vishay

- 1 sensor de corrente do painel solar por efeito Hall (ACS711)

- 1 sensor de tensão do painel solar (divisor resistivo, tensão reduzida sendo medida no ADC) 
- Barramento de comunicação com a placa controladora: i2c. Com isso, é possível acessar todos os sensores de todas as placas de sensoriamento por uma única interface, alterando-se apenas o endereço de cada uma delas no barramento (variando-se os resistores em cada placa de sensoriamento que configura o seu endereço)

- Alimentação da placa é proveniente da placa controladora, 3,3 Vdc

O sensor de temperatura e umidade já tem sua saída em i2c nativamente. Já os sinais de luminosidade, tensão e corrente são primeiramente tratados por um circuito de condicionamento - como se pode observar nas figuras a seguir -, para então serem digitalizados por um ADC (ADS1115 da Texas Instruments), sendo que este último já possui interface i2c para transmissão dos dados para a placa controladora.

\subsubsection{Condicionamento de sinal do fotodiodo}

Na Figura 10, encontra-se o circuito de condicionamento de sinal do fotodiodo. Esse circuito é basicamente um amplificador de transimpedância, o que garante que a tensão de saída "IN3" seja diretamente proporcional à radiação incidente no fotodiodo. Nesse circuito, o componente AD8639 da Analog Devices é um amplificador operacional de saída bem controlada, com baixo offset $(3 \mu \mathrm{V}), \operatorname{drift}\left(0,01 \mu \mathrm{V} /{ }^{\circ} \mathrm{C}\right)$ e corrente de polarização (menor do que 100 pA), sendo adequado à essa aplicação por possuir baixo ruído e boa 
relação sinal-ruído. O resistor de 50k realiza a realimentação desse sistema, fazendo com que a tensão de saída seja numericamente equivalente à corrente do fotodiodo multiplicada pela sua resistência em baixas frequências, uma vez que nessas condições a entrada inversora do amplificador operacional está no mesmo potencial da entrada não-inversora. O capacitor C7 ajusta a capacitância de saída do circuito, garantindo a estabilidade da malha de realimentação em frequências mais altas. Por fim, o resistor de $10 \mathrm{k}$ e o capacitor de $47 \mathrm{nF}$ formam um filtro passa-baixa de $338,63 \mathrm{~Hz}$, o que servirá para evitar rebatimento no conversor AD (evitar frequências acima de $120 \mathrm{kHz}$ para esta topologia e valores de realimentação), bem como fará com que o sinal fique abaixo da frequência Nyquist do conversor (para o ADS1115, a frequência máxima de amostragem é de 860 amostras/s, portanto com frequência Nyquist de $430 \mathrm{~Hz}$ no máximo para o sinal). Assim, o filtro passabaixa indicado atinge esses dois objetivos.

Por fim, a saída desse circuito Vo, representada na figura por "IN3" , pode ser descrito como sendo:

$V o=-R \cdot E_{\text {inoidente }} \cdot A_{\text {sensivel }} \cdot S(\mathrm{~S})$

Onde:

Vo = tensão de saída, em Volts

$\mathrm{R}=$ resistência de realimentação do amplificador, em Ohms 
$E_{\text {incidente }}=$ potência luminosa incidente no sensor, em Watts por centímetro quadrado

$A_{\text {sensivel }}$ área sensível à radiação, em centímetros quadrados

$S(\lambda)=$ sensitividade espectral relativa em função do comprimento de onda da luz, em A/W

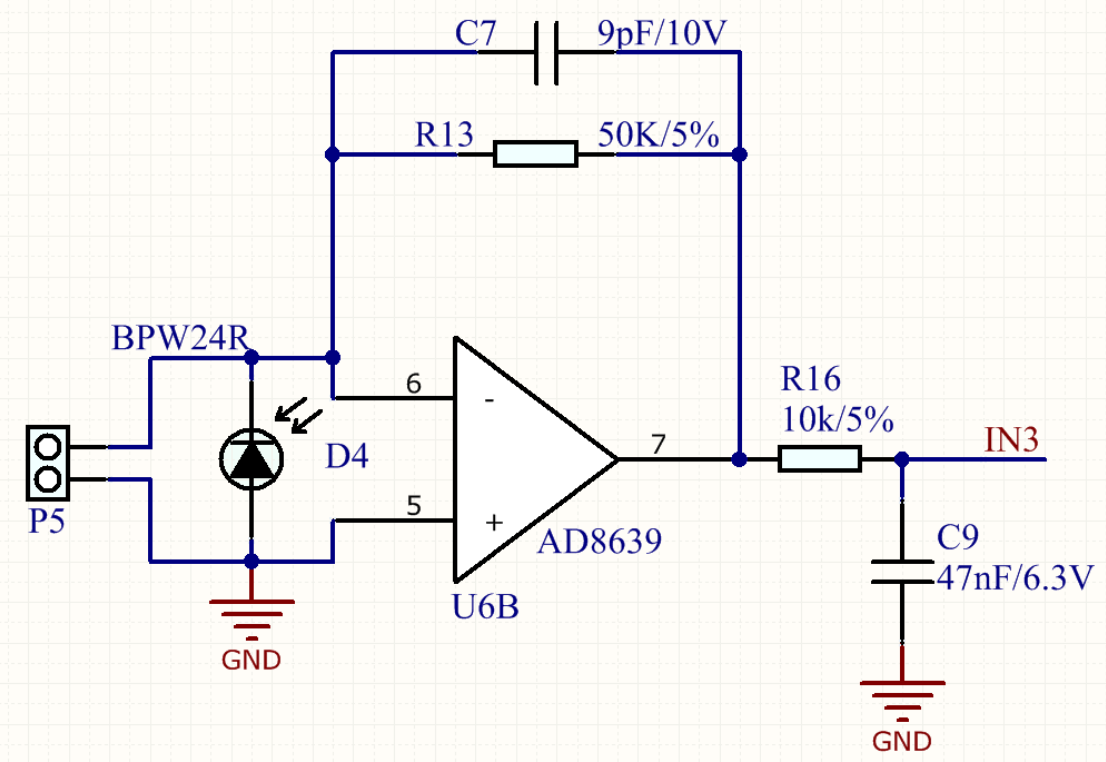

Figura 10 - Circuito de condicionamento de sinal do fotodiodo 


\subsubsection{Condicionamento de sinal de corrente de célula solar}

A Figura 11 contém o circuito de condicionamento do sinal de corrente da célula solar. O Cl ACS711 é um sensor linear de corrente por efeito Hall, e está sendo usado para converter o sinal de corrente de célula solar em uma tensão mensurável pelo ADC, representada na figura por "IN4" . Um painel típico que se pretende usar possui corrente máxima em torno de $2 \mathrm{~A}$, ao passo que este sensor está otimizado para o intervalo de até $12,5 \mathrm{~A}$.

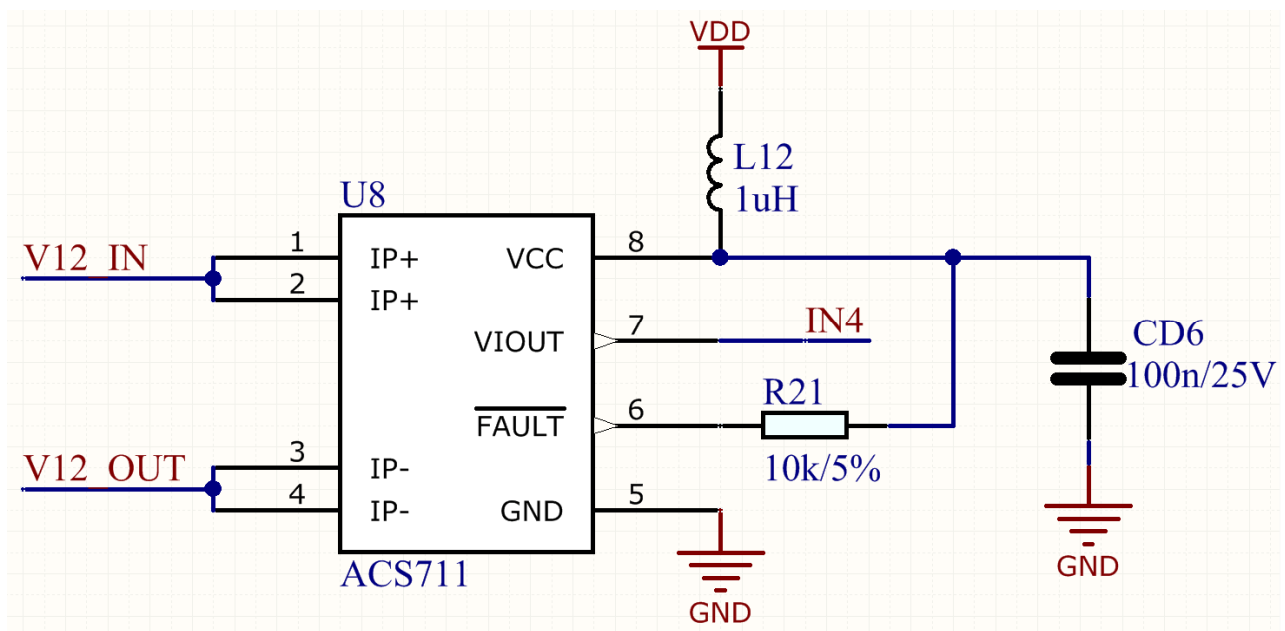

Figura 11 - Circuito de condicionamento de sinal de corrente da célula solar 


\subsubsection{Condicionamento de sinal de tensão de célula solar}

O circuito da Figura 12 demonstra o condicionamento de sinal de tensão de célula solar. Uma vez que o conversor analógico-digital está preparado para converter tensões menores do que $\mathrm{VDD}=3,3 \mathrm{Vdc}$, e como o sinal a ser medido é esperado que esteja no intervalo de 0 a $12 \mathrm{Vdc}$, um divisor resistivo de $1: 0,248$ aproximadamente garante que a tensão de saída "IN5" não irá ultrapassar 3,3 Vdc se a tensão de entrada "V12 IN" não ultrapassar $13,3 \mathrm{Vdc}$

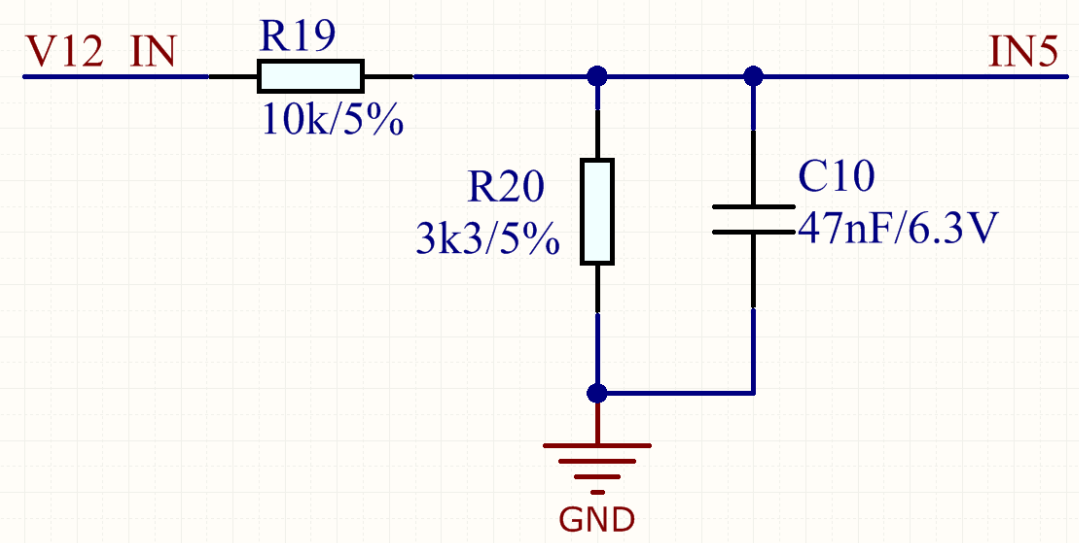

Figura 12 - Circuito de condicionamento de sinal de tensão da célula solar 


\subsubsection{Fotodiodos}

A placa de sensoriamento desenvolvida está apresentada nas Figura 13 e 14 .

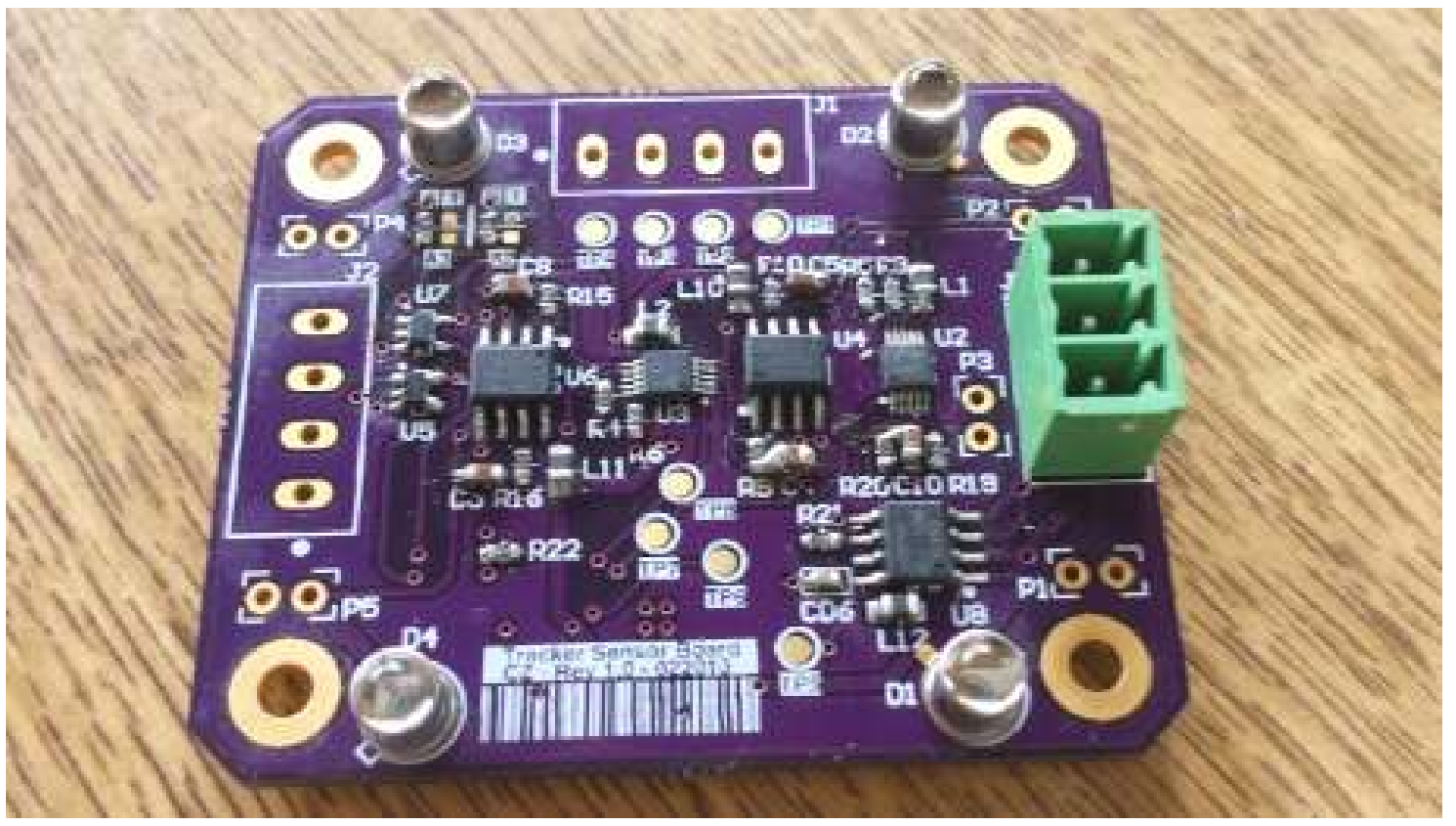

Figura 13 - Detalhe da face superior da placa de sensoriamento

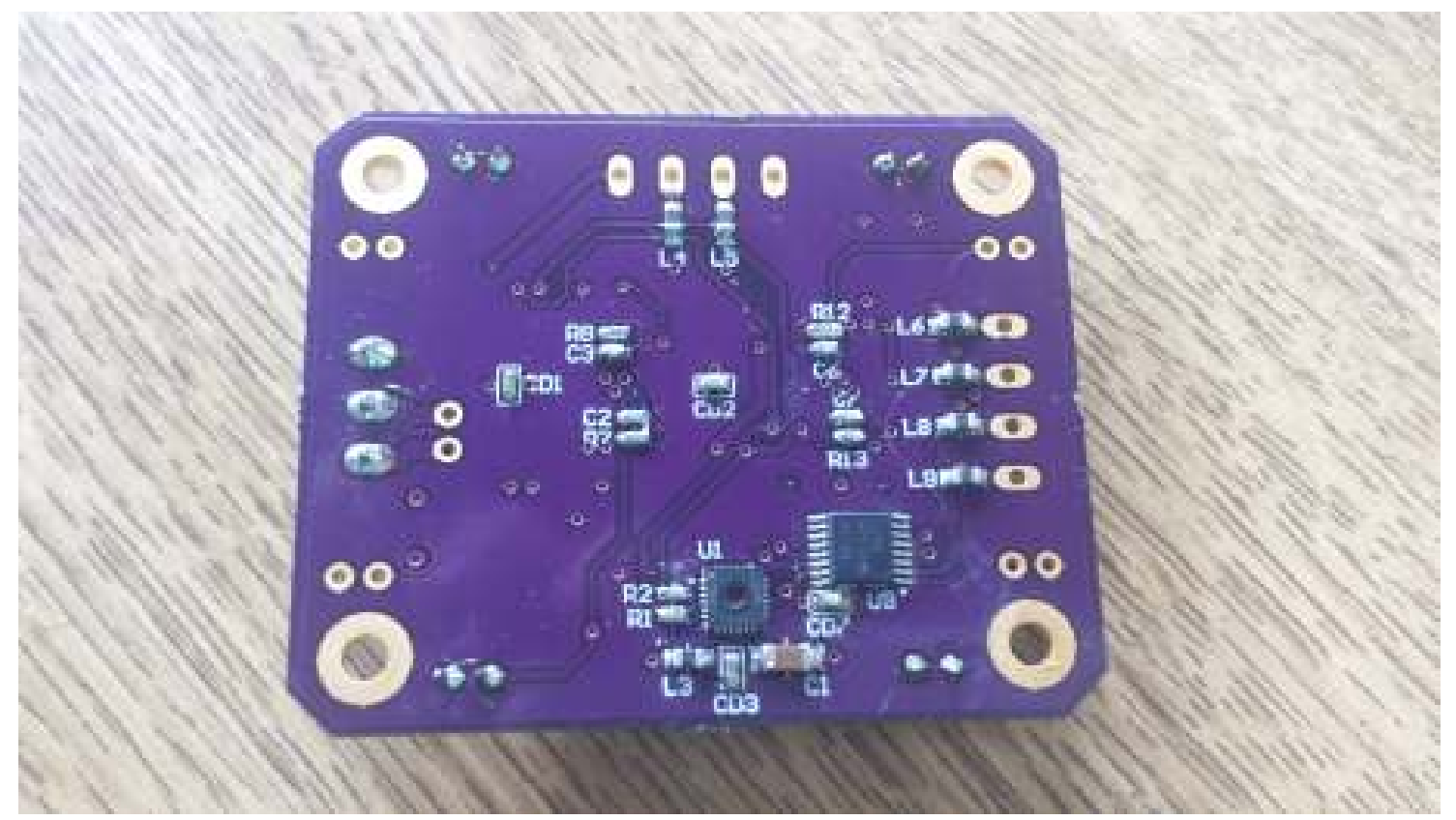

Figura 14 - Detalhe da face inferior da placa de sensoriamento 
O Anexo 2 apresenta o circuito esquemático da placa de sensoriamento.

Como é possível observar na Figura 13, cada placa de sensoriamento tem em sua face superior 4 sensores de luminosidade (D1, D2, D3 e D4). Esses sensores são BPW24R da Vishay, os quais são fotodiodos planares de silício de alta sensibilidade. Eles são hermeticamente selados com uma cobertura metálica e uma lente de vidro existe no seu topo. Esses sensores possuem sensibilidade a comprimentos de onda entre 400 e $1100 \mathrm{~nm}$, tendo o pico de sensibilidade em 900 nm, como mostra o gráfico da Figura 15. Assim, pode-se dizer que eles são adequados para detectar luz solar, a qual se apresenta num intervalo amplo de comprimentos de onda, mas se concentra na região visível (47 \%), entre 380 e 780 nm, e na região de infravermelho (46 \%) do espectro, acima de $780 \mathrm{~nm}[11]$. 


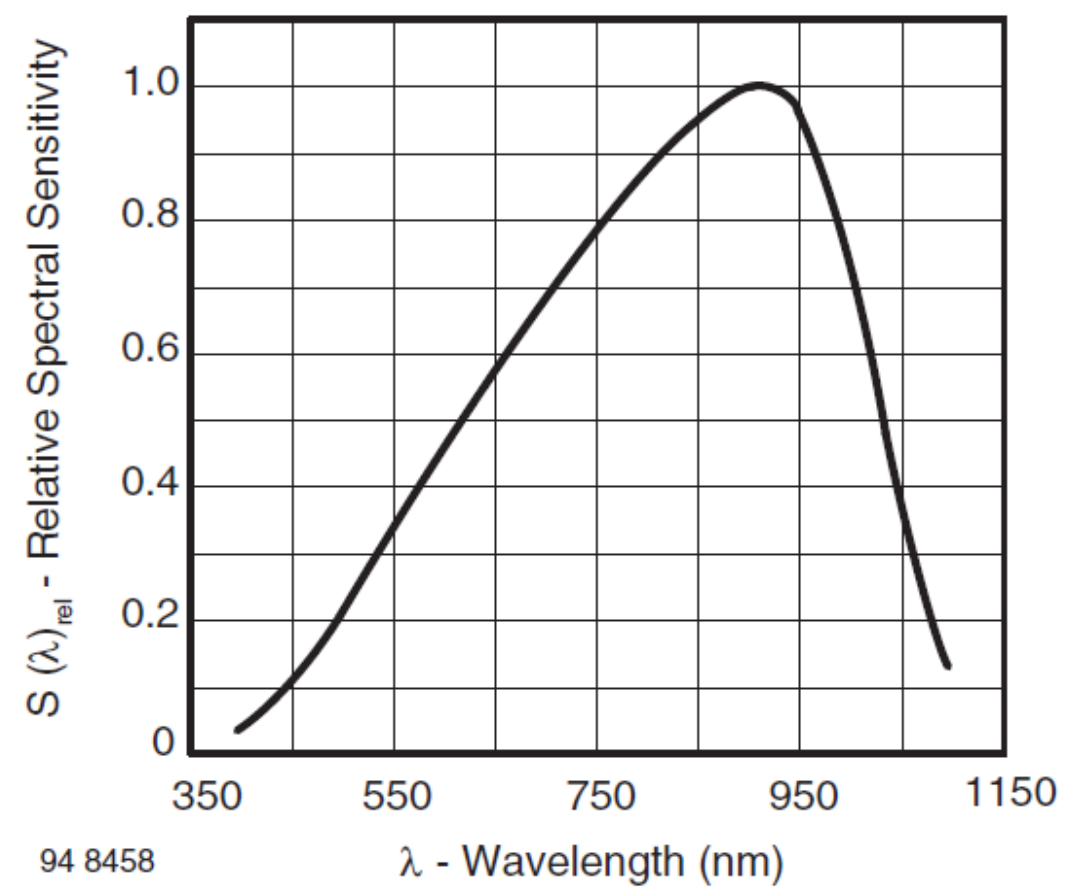

Figura 15 - Sensibilidade espectral relativa x Comprimento de onda para o BPW24R

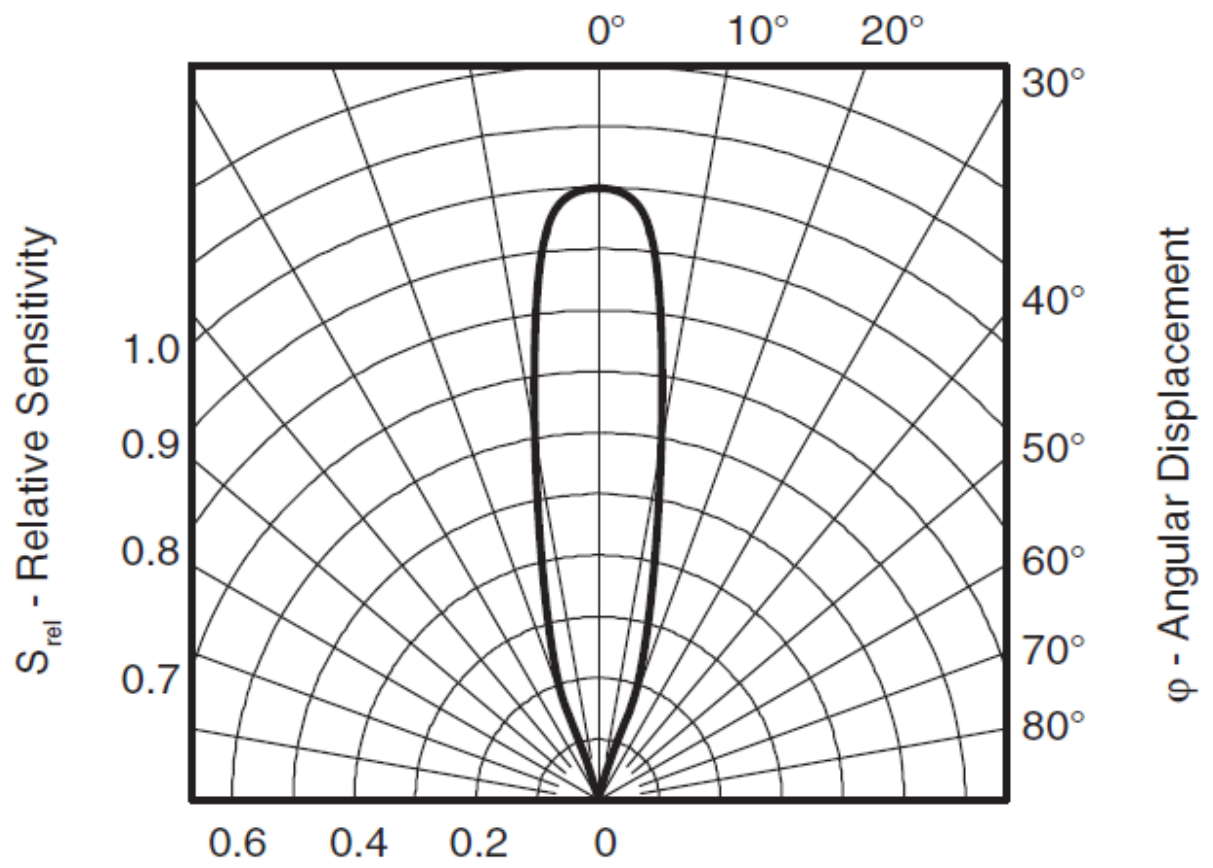

Figura 16 - Sensibilidade à radiação x Deslocamento angular para o BPW24R 
Esse sensor possui sensibilidade angular máxima (100\%) a 0 graus de incidência dos raios solares com a normal, sendo que essa sensibilidade cai para 50 \% quando o ângulo de incidência é de 12 graus. Isso pode ser observado na Figura 16.

Pelo exposto, a disposição de 4 fotodiodos na placa de sensoriamento, um em cada extremidade, tem a capacidade de fornecer adequadas informações sobre a direção para a qual o sol está se movimentando, teoricamente sem necessidade de outra paca de sensoriamento sobre o painel solar. Essa informação seria tirada da diferença de radiação detectada entre os sensores, uma vez que poucos graus de deslocamento angular do raio incidente já causa uma queda bastante considerável na sensibilidade do dispositivo à radiação solar. Contudo, reserva-se para a execução do experimento a determinação da necessidade ou não da presença de uma segunda placa de sensoriamento por sobre o painel solar.

No caso da montagem com apenas uma placa de sensoriamento, planeja-se fixá-la em uma região próxima ao centro do painel; no caso da montagem com duas placas de sensoriamento, planeja-se montá-las nas extremidades voltadas para o leste e oeste do painel. 


\subsubsection{Servomotor}

O servomotor utilizado neste trabalho foi o TowerPro MG995, facilmente encontrado em carrinhos de controle remoto e em diversas aplicações de modelismo. Suas especificações são:

- Peso: $55 \mathrm{~g}$

- Dimensões: 40,7 x 19,7 x 42,9 mm

- Torque: $9,4 \mathrm{~km} / \mathrm{cm}$ a $4,8 \mathrm{~V}$ ou $11 \mathrm{~kg} / \mathrm{cm}$ a $6 \mathrm{~V}$

- Velocidade: $0,2 \mathrm{~s} / 60 \mathrm{graus}$ a $4,8 \mathrm{~V}$ ou $0,16 \mathrm{~s} / 60 \mathrm{graus}$ a $6 \mathrm{~V}$

- Tensão de alimentação: de 4,8 a 6 V

Sua alimentação foi escolhida para ser $6 \mathrm{~V}$, principalmente pela maior disponibilidade de torque, e será feita pela bateria. A Figura 17 apresenta uma imagem com o servomotor em utilização.

Um dos motivos para a escolha do servomotor para esta aplicação foi a facilidade de controle de posição do mesmo, evitando a necessidade de um sistema de controle mais elaborado (como um PID que seria necessário possivelmente no caso de se usar um motor DC com sensor de posição). Uma segunda vantagem que pode ser afirmada é a de que servomotores não precisam consumir muita corrente para se manterem parados na posição que foi determinada. 
Além disso, se um motor de passo fosse usado, periodicamente seria necessária a recalibração do sistema com relação aos passos e o ângulo final esperado. Isso se deve ao fato de que escorregamentos ocorridos por excesso de carga no motor de passo faria com que o mesmo perdesse a correspondência correta entre passos do motor e ângulo, gerando a necessidade de giro até o final do curso para os dois lados afim de se determinar novamente essa correspondência (assim como ocorre com impressoras a jato de tinta).

Contudo, servomotores são notoriamente mais caros do que os de passo e DC, e isso precisa ser levado em consideração no caso desta pesquisa ser usada como base em uma aplicação de geração fotovoltaica de energia.

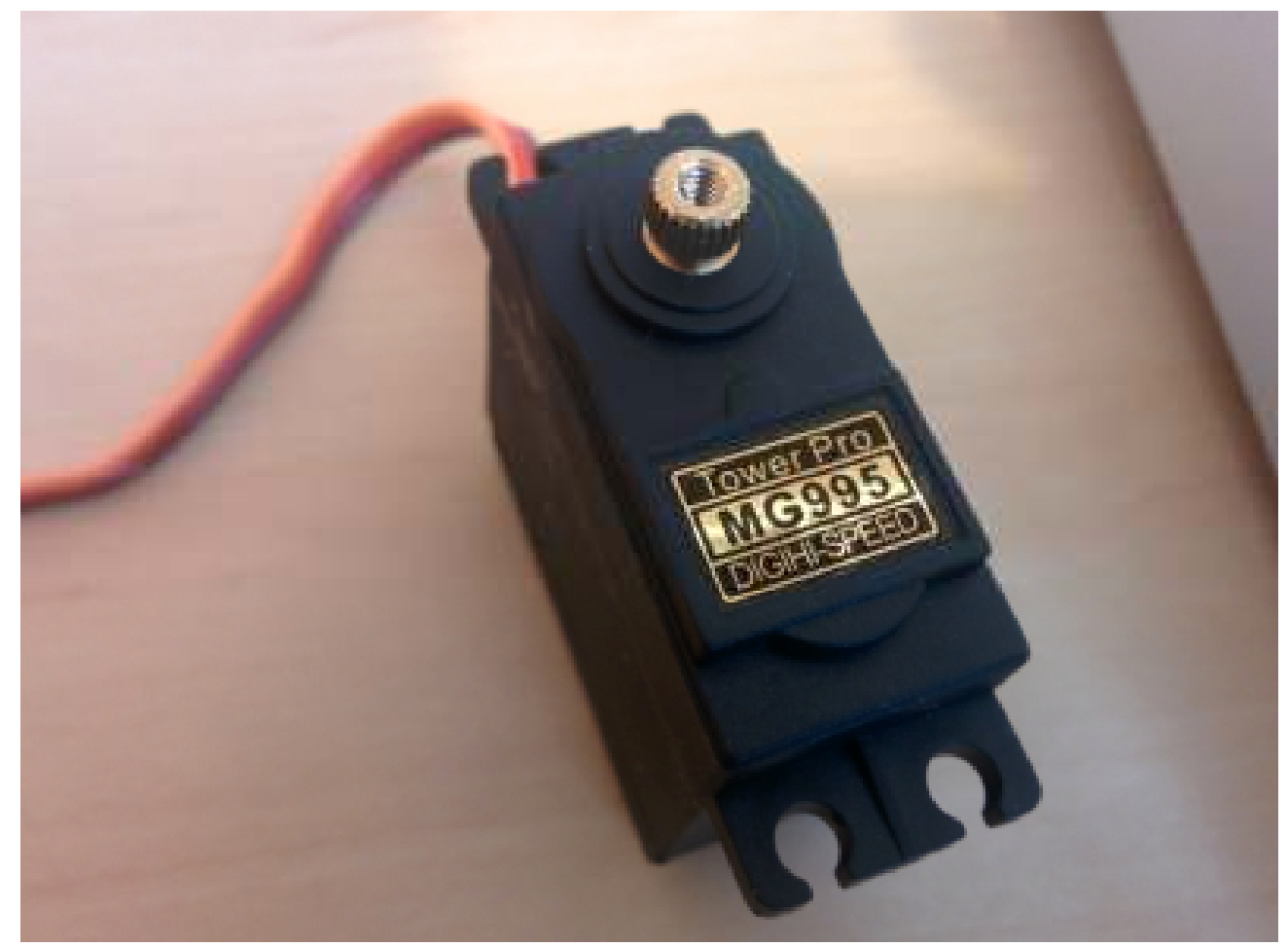

Figura 17-Servomotor utilizado 


\subsubsection{Suporte Mecânico para o Painel Solar}

O suporte mecânico é feito de alumínio, devido ao seu bom balanceamento entre peso da estrutura, resistência mecânica e preço. Esse suporte possui dois graus de liberdade de rotação para o painel solar, a saber:

1. Eixo de rotação para que o servomotor seja instalado, permitindo que a rotação do painel seja possível durante o dia, acompanhando assim a variação de posição diária do Sol;

2. Eixo de rotação manual, para que se ajuste o ângulo de inclinação de acordo com a altitude média do Sol durante as estações do ano. Este segundo grau de liberdade se justifica para que se atinja o máximo de eficiência do sistema em qualquer estação do ano, dada a variação da altitude do Sol durante as estações do ano.

O suporte mecânico foi projetado especialmente para o painel solar YL10P17b, com os pinos de fixação nas distâncias e dimensões próprias para esse painel. Além disso, foi projetado para ser integrado a um tripé, diminuindo assim o custo do projeto customizado. A seguir se encontram imagens do projeto mecânico do suporte. 


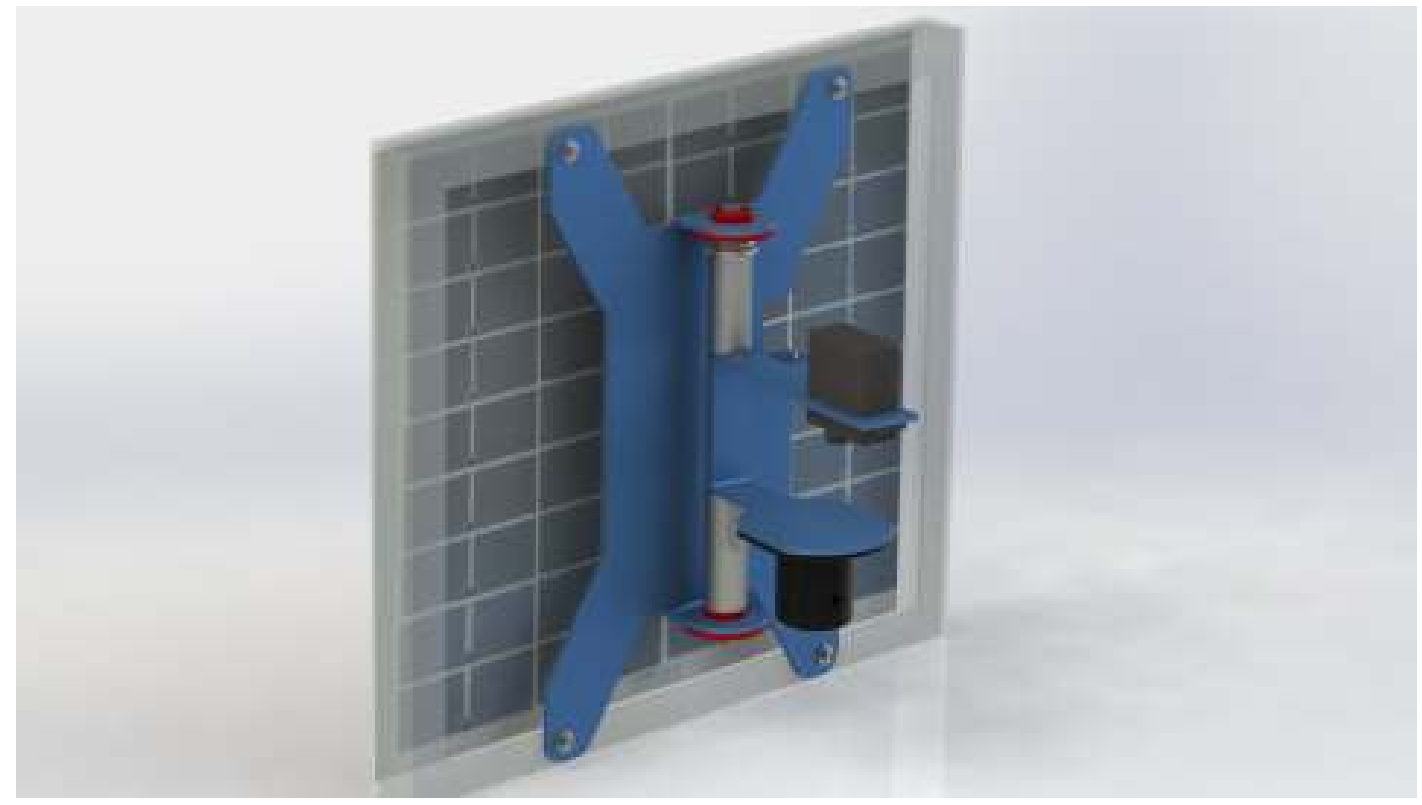

Figura 18 - Projeto mecânico do suporte para o painel solar (1)

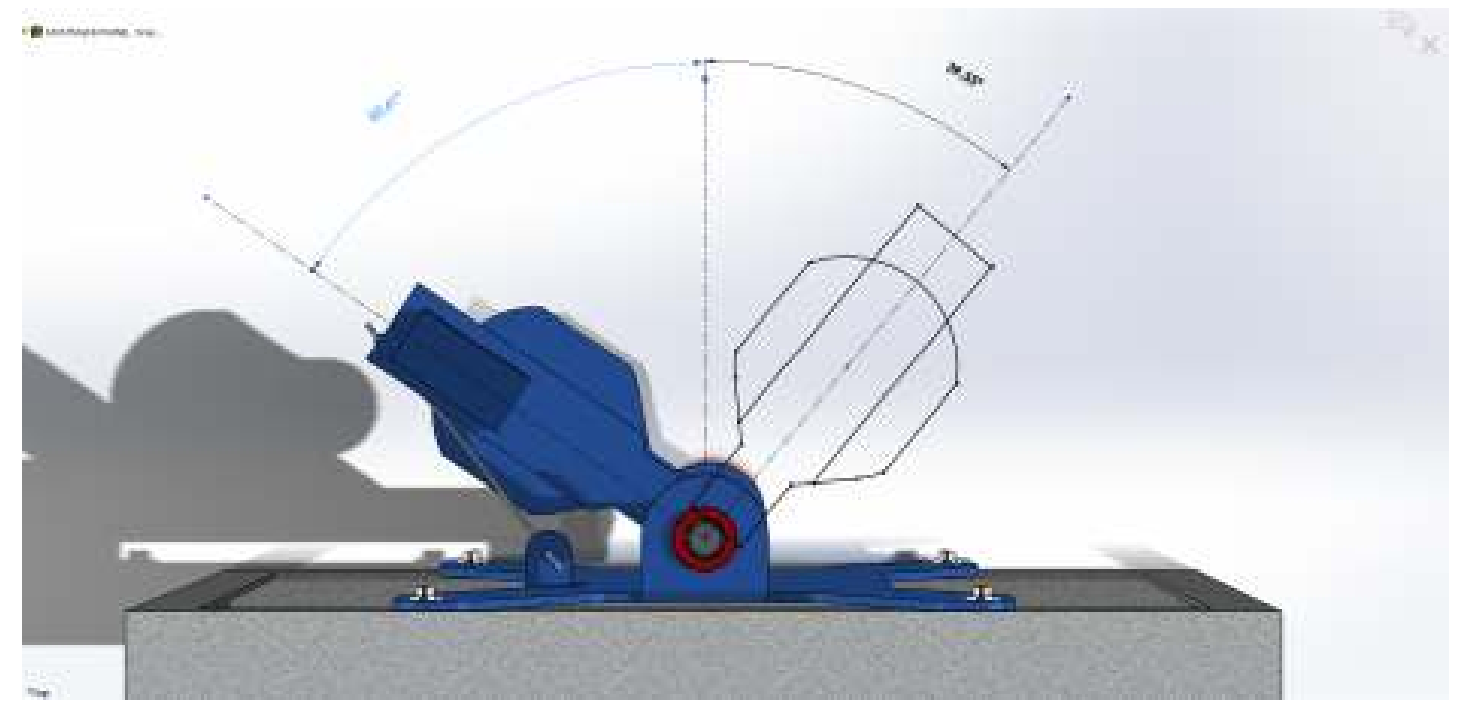

Figura 19 - Projeto mecânico do suporte para o painel solar (2)

Esse suporte, após confeccionado, foi fixado a um tripé de altura de $1 \mathrm{~m}$, de forma a deixar o experimento com uma altura razoável em relação ao chão. Em uma aplicação comercial, seria interessante projetar o suporte para fixação em locais mais apropriados, como telhados de casas, fixação em paredes ou 
até mesmo algo mais baixo para ser mantido no chão de uma usina de energia solar, de forma a não fazer sombra de um painel sobre o outro.

O servomotor foi convenientemente fixado na parte inferior do painel, de forma a permitir o acionamento da rotação do sistema com a ajuda de um braço metálico entre o eixo do motor e a parte móvel do suporte. Abaixo se encontram algumas fotos da estrutura montada, ainda sem o painel solar e placas de controle e sensoriamento.

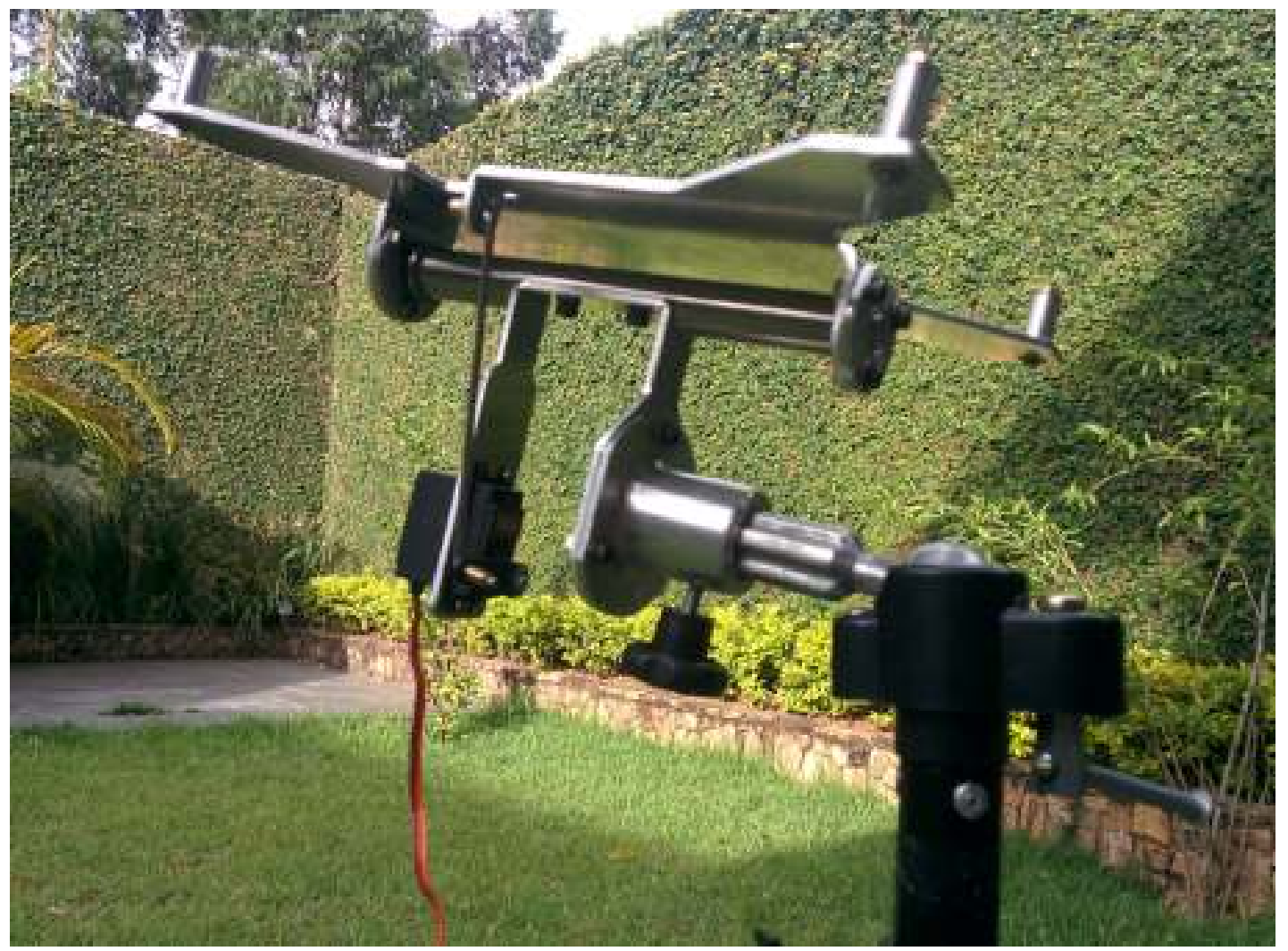

Figura 20 - Estrutura sendo montada para receber o painel solar (1) 


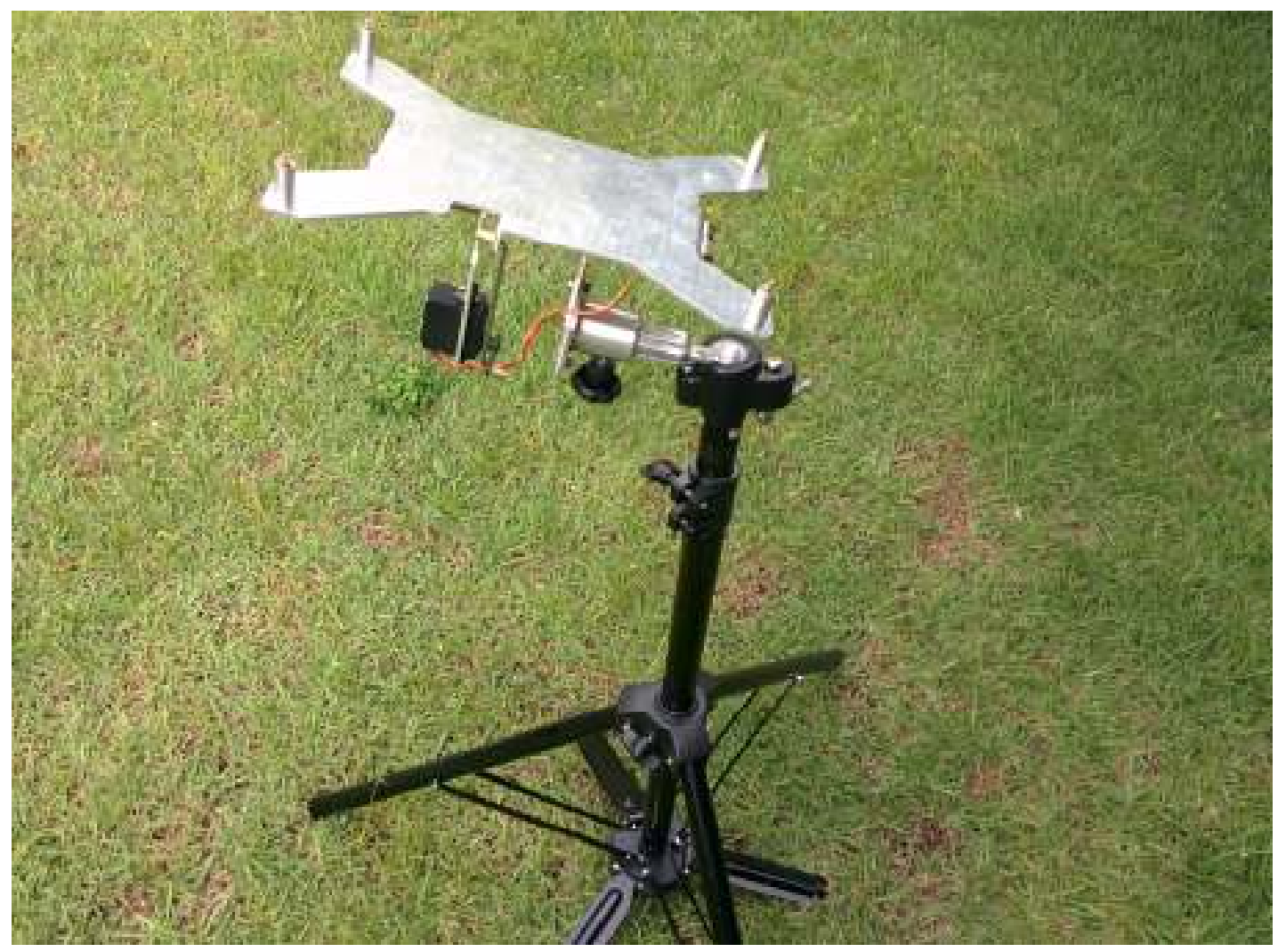

Figura 21 - Estrutura sendo montada para receber o painel solar (2)

O painel então foi parafusado na parte superior do suporte mecânico. 
A Figura 22 demonstra essa fase da montagem.

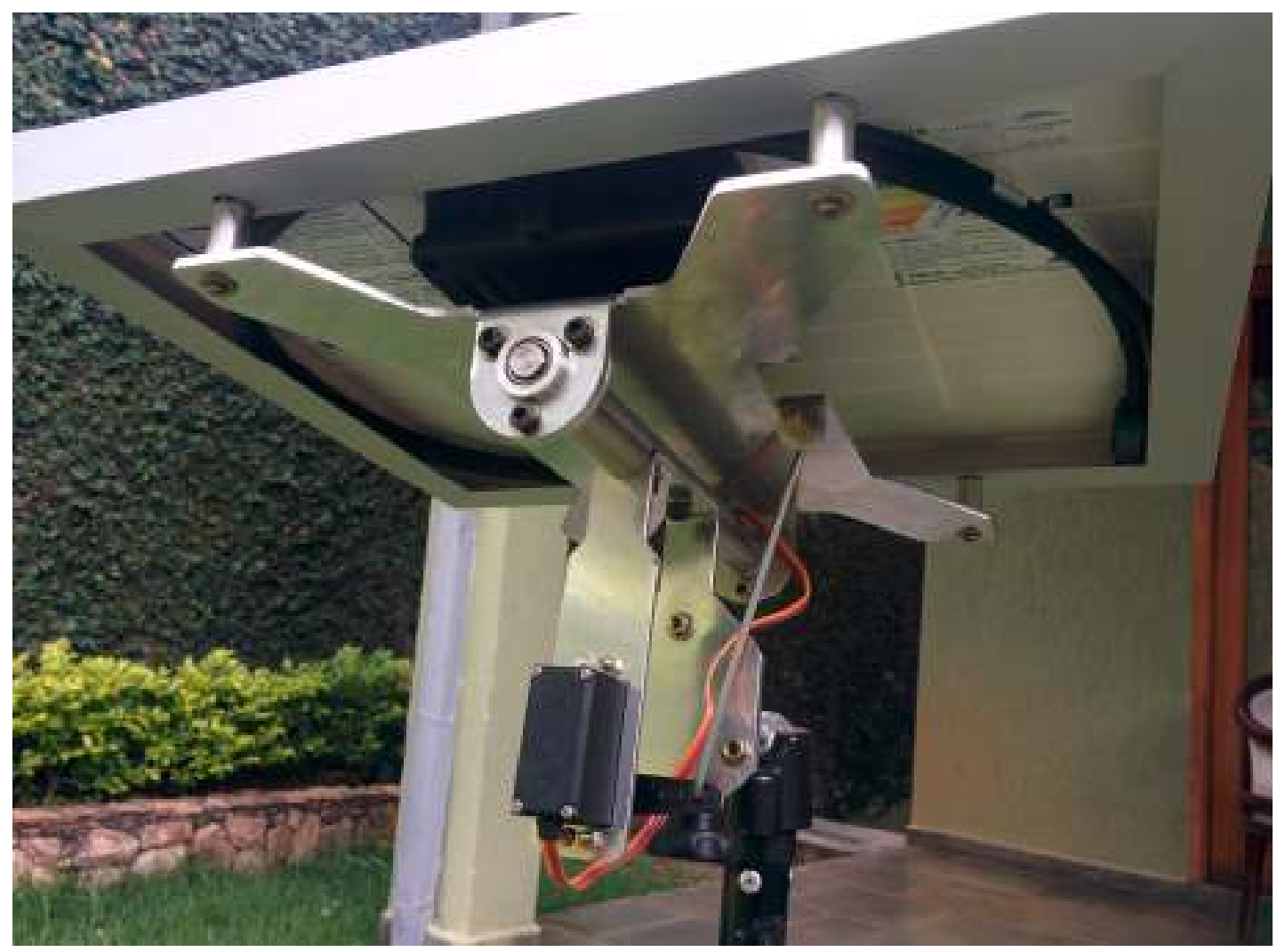

Figura 22 - Painel solar fixado à estrutura mecânica (1) 


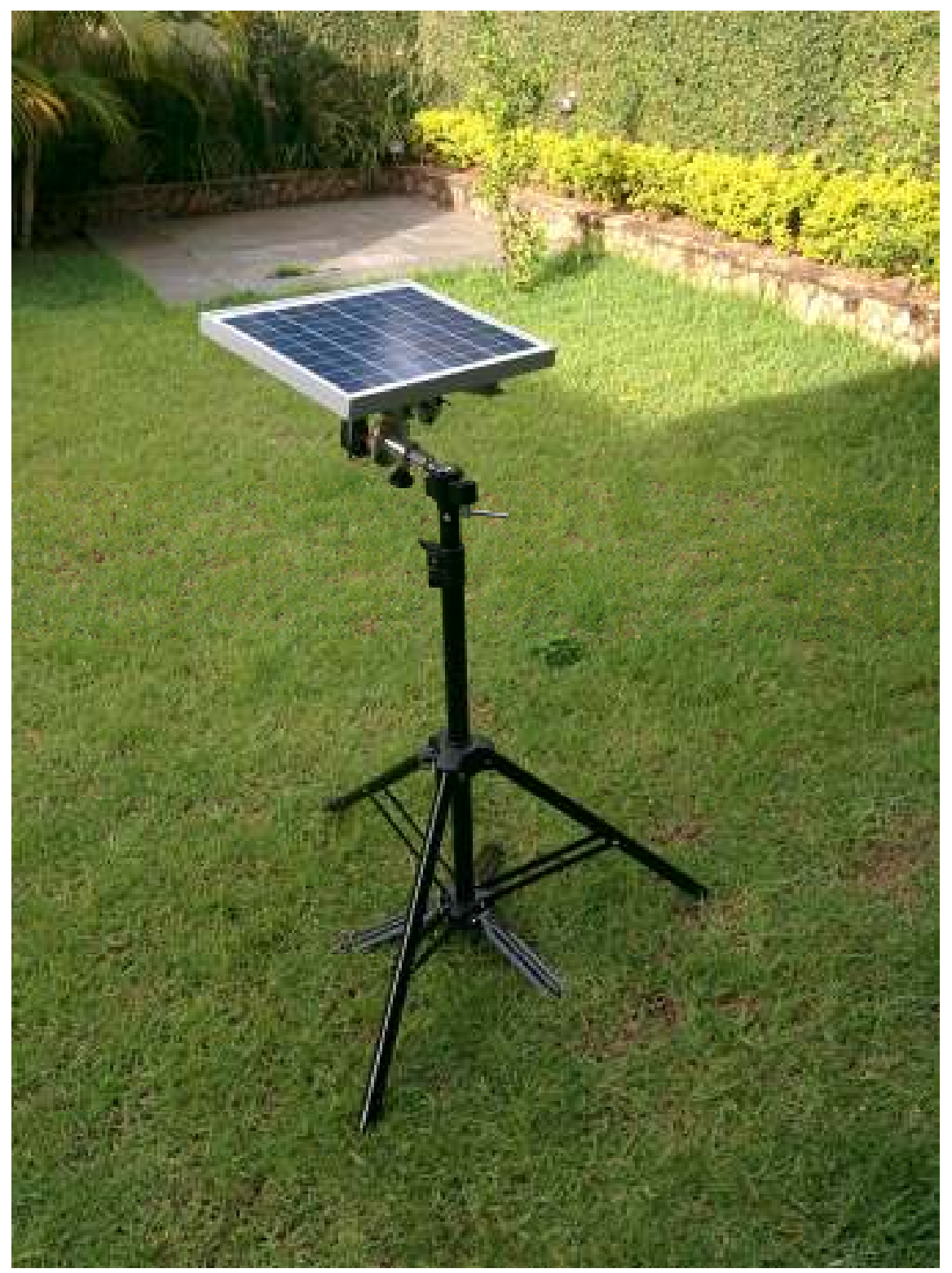

Figura 23 - Painel solar fixado à estrutura mecânica (2)

Por fim, a placa de controle foi fixada a parte inferior da estrutura, bem como a placa de sensoriamento foi fixada na parte superior. 


\subsubsection{Bateria}

A bateria usada neste experimento é uma bateria de automóvel de chumboácido, a qual será de 12 Vdc com uma carga de aproximadamente 40 Ah.

O sistema será integralmente alimentado por bateria, ou seja, as placas de controle, motor e sensoriamento estarão se baseando na carga da mesma. Com isso, o sucesso do experimento está diretamente dependente da necessidade da geração de energia elétrica ser maior do que o gasto da mesma pelo sistema.

\subsubsection{Diagrama de Distribuição do Sistema}

O diagrama de distribuição do sistema se encontra no Anexo 3, ao final deste documento. 


\subsection{Variantes do Experimento}

O experimento apresenta as seguintes variantes:

1. Painel fixo, sem fazer rastreamento

2. Painel fazendo rastreamento, seguindo o sol via sensores

3. Painel fazendo rastreamento, seguindo uma trajetória pré-definida baseada somente nas horas do dia e na posição geográfica do painel

4. Idem 3, porém com correções baseadas no movimento do sol detectado pelos sensores quando necessário

O objetivo dessas variantes de experimento é chegar a uma conclusão acerca da necessidade do rastreamento solar frente à eficiência obtida, bem como a necessidade de se rastrear a posição do sol baseando-se em sensores ao invés de se ter uma trajetória pré-definida - o que levaria a um menor custo de hardware. 


\subsection{Indicadores a Serem Medidos}

Para cada uma das variantes descritas no item anterior, deverão ser observados os seguintes valores, instantaneamente:

- Tensão e corrente do painel solar

- Energia elétrica gerada

- Radiação solar

- Umidade relativa

- Temperatura na superfície do painel solar

- Medida qualitativa: nas variantes do experimento com rastreamento solar, observar a posição do painel frente à posição do sol (checagem básica do método de rastreamento)

- Energia armazenada em bateria após um período determinado de funcionamento do sistema 


\subsection{Metodologia}

\subsubsection{Tomada de Medidas}

Durante o dia inteiro os dados do item 3.3 serão tomados e armazenados na memória flash da placa controladora. Para as variantes do experimento nas quais há rastreamento solar, a posição angular do painel será também armazenada.

Será também observado o quanto de energia foi armazenado em bateria em cada uma das variantes de experimento após um certo período, que pode ser de um dia, uma semana, etc. Essa medida é muito importante, pois é dela que virá a observação sobre a eficiência do sistema. Por exemplo, se o rastreamento solar fez com que a energia gerada em um certo período tenha aumentado, porém com um gasto de energia da bateria que excede esse ganho, então concluir-se-á que o processo não obteve sucesso.

Todos os valores obtidos da placa de sensoriamento são transmitidos via i2c para a placa controladora, a qual não só armazenará os dados para uso e transmissão, mas também terá a inteligência para se adaptar à situação atual do sistema com objetivo de aumentar a eficiência do mesmo. Isso será visto no item a seguir.

É interessante apontar que os dados armazenados pela placa controladora, bem como a detecção do posicionamento solar podem ser aproveitados por 
outros sistemas semelhantes a este. Assim, em uma situação na qual vários sistemas solares com rastreador estejam próximos uns aos outros, as informações colhidas e processadas pelo sistema descrito neste trabalho podem ser passadas a esses outros sistemas próximos, tornando assim possível um menor custo de hardware nesses sistemas por não necessitarem de placas de sensores, além de poderem ser montados com uma placa controladora mais simples [2]. 


\subsubsection{Algoritmos}

O algoritmo de rastreamento solar será desenvolvido com o objetivo de garantir que os raios solares incidentes no painel solar formem um ângulo o mais próximo possível de 90 graus, no maior período possível durante o dia.

Sabe-se que o rastreamento cobriria teoricamente um ângulo de 180 graus, no sentido Leste-Oeste. Contudo, considerando que o ângulo de 0 graus do painel seja com ele na posição de altitude 0 graus, o rastreamento solar com ângulo superior a 60 graus para qualquer um dos lados leva a ganho de energia muito baixo. Como visto em [4], a ângulos maiores que 60 graus de inclinação do painel solar em relação à sua posição de altitude 0 graus, a perda de conversão de energia solar em elétrica em comparação com um modelo ideal de rastreamento solar é de menos de $1 \%$. Assim, o sistema de rastreamento fará excursão máxima de 60 graus para ambos os lados.

Um dos algoritmos mais importantes do sistema será o de calibração da operação de rastreamento. Esse algoritmo irá permitir que o sistema determinar que ângulo final o sistema precisará assumir para anular a diferença de radiação entre os sensores da mesma placa e/ou de placas de sensoriamento distintas dispostas sobre o painel solar, chegando a uma situação de posicionamento da superfície do painel solar a 90 graus em relação aos raios solares incidentes. 
A adaptação citada no item 3.4 .1 se dará de forma iterativa. O sistema terá internamente uma configuração de passo do rastreamento solar. Esse passo consiste na mínima demanda por deslocamento angular do motor que de fato acarretará em movimento da estrutura. Por exemplo, assumindo que essa configuração mínima esteja em 1 grau, inicialmente. Quando o sistema detectar o movimento do sol, a diferença de radiação detectada entre os sensores da placa de sensoriamento será convertida em um ângulo para se deslocar, usando para isso os dados de calibração previamente realizada. Como o parâmetro de passo está em 1 grau do motor, quando a conversão para atuação do motor atingir 1 grau o movimento será iniciado. Contudo, se o passo estivesse configurado em 5 graus, somente quando a conversão atingisse esse valor que o movimento seria feito.

Além disso, será implementado também o algoritmo do SPA (Solar Position Algorithm) no NREL [19], o qual fornece a posição de zênite e azimute do Sol entre os anos de -2000 e 6000 , com incerteza de $+/-0,0003$ graus. Para isso, são necessárias as informações de: data e hora, latitude e longitude, elevação, temperatura, entre outros. O NREL disponibiliza uma implementação do SPA em $C$, também usada no desenvolvimento do firmware do sistema. Assim, a variante do experimento que não se baseará em sensores para o rastreamento usará este algoritmo para seguir o Sol.

Sabe-se que retirar a estrutura móvel da inércia inicial é custoso em energia, pois primeiro deverá ser vencido o atrito estático para depois atingir a 
posição determinada. Como se sabe, servomotores possuem uma corrente quiescente relativamente baixa, aumentando quando uma atuação é requerida. Concluindo, o sistema considerará que cada início de movimento será custoso para a eficiência geral, e tentará adaptar o passo do rastreamento para otimizar esse processo. Essa adaptação se dará iterativamente, aumentando o valor do parâmetro de passo e observando a eficiência de geração de energia elétrica obtida: enquanto a eficiência não cair devido ao passo, o parâmetro de passo será incrementado em graus; quando cair, esse processo voltará atrás em sua alteração, buscando assim o ponto ótimo.

Por fim, haverá mais um algoritmo de falha segura do sistema. Se em algum momento os sensores não conseguirem mais determinar o movimento do sol (devido a nebulosidade ou outros fatores que possam atrapalhar o desempenho dos sensores), ou se o aumento do parâmetro de passo do rastreamento causar uma perda irreversível da posição do sol, o sistema adotará a posição pré-determinada pelo horário e posição geográfica para rotacionar o painel. Se e quando a medida puder ser refeita, o rastreamento via sensor pode ser retomado.

O fluxograma do algoritmo implementado está presente na Figura 24. 


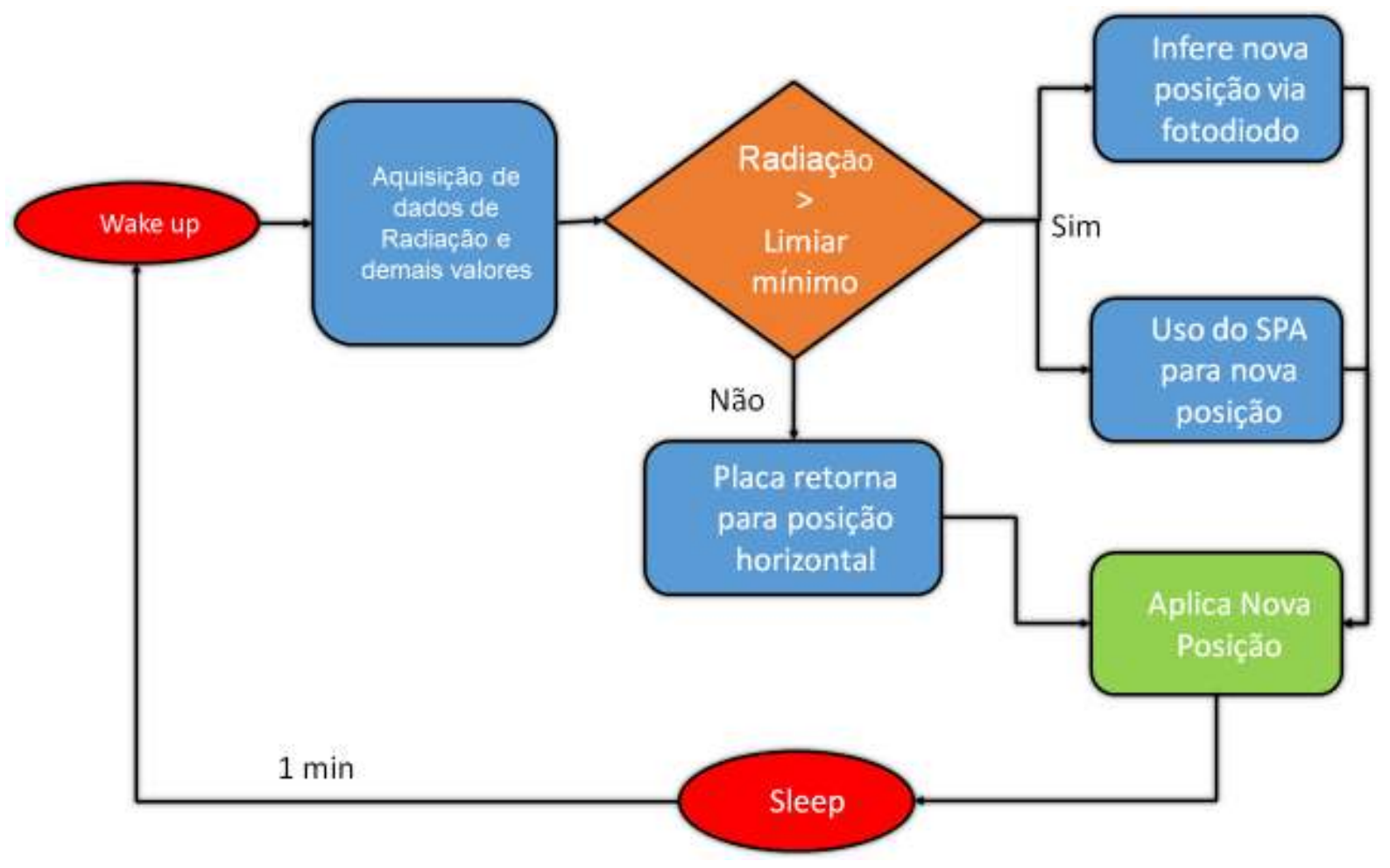

Figura 24 - Fluxograma do algoritmo utilizado 


\section{Resultados Esperados}

Ao final dos experimentos, se espera chegar a uma conclusão acerca de:

- Porcentagem de aumento de eficiência das variantes com rastreamento em relação à variante fixa

- Qual das variantes gerou mais energia elétrica em um mesmo período de tempo. Essa conclusão será difícil de obter se somente uma estrutura estiver montada, pois nesse caso as variantes de experimento serão realizadas em dias diferentes, portanto em condições diferentes

- Se houve algum indício de diminuição de eficiência energética do sistema devido a elevadas temperaturas na superfície do painel solar

- Nas variantes de experimento com rastreamento, qual foi o valor de passo de rastreamento ótimo que foi atingido 


\section{Resultados e Comentários}

Após a montagem do experimento, o firmware em desenvolvimento foi testado e modificado em diversos pontos, de forma a se atingir o objetivo deste estudo. Foram identificados alguns problemas no sistema, a saber:

- O suporte mecânico foi projetado com o servomotor posicionado de forma central, porém o ponto de junção do suporte com o braço do servomotor ficou fora do centro. Isso não seria um problema caso o braço utilizado fosse suficientemente comprido. Contudo, seu tamanho inferior ao ideal fez com que a máxima excursão da rotação ficasse abaixo dos 60 graus planejados, com 39,55 graus para um lado e 55,61 graus para o outro.

- Na placa de controle, o pino para controle de PWM do servomotor foi equivocadamente projetado com um GPIO (General Purpose In Out pin) e não com o pino correto do microcontrolador LPC2387 específico para este fim. Com isso, o controle de duty-cycledo sinal de controle teve de ser feito por um GPIO que teve sua saída controlada por um timer de hardware do microcontrolador.

- Ausência de uma forma de o sistema obter a informação de carga da bateria. 
- Projeto dos fotodiodos apresentou problemas para poderem ser utilizados no controle de posicionamento do painel. Eles precisariam estar a uma distância consideravelmente maior entre si para poderem apresentar valores diferenciais de medida, de forma a se poder inferir o próximo movimento do painel solar; um filtro para reduzir a intensidade da irradiância sobre os fotodiodos, pois sem isso eles são levados ao estado de saturação com grande facilidade.

Esses problemas identificados devem ser corrigidos em uma nova implementação desse sistema para um resultado mais satisfatório. Contudo, inferiu-se que esses problemas não inviabilizariam a experiência, ressalvandose que a correção dos mesmos melhorará o desempenho geral.

\subsection{Medidas Obtidas}

O experimento foi executado diversas vezes - por volta de 40 dias de teste ao todo -, por forma a se adaptar os erros cometidos no desenvolvimento do software de controle de posição, de aquisição de medidas, bem como no de transmissão de dados via Ethernet. Optou-se por não realizar medidas em dias chuvosos devido à ausência de vedação das partes elétricas do sistema.

Em função de haver somente um sistema implementado, tornou-se impossível a comparação entre técnicas de rastreamento distintas, algoritmos, ou até mesmo entre sistemas com e sem rastreamento solar. Assim, a análise foi 
realizada por comparações entre dias razoavelmente semelhantes, usando-se o único sistema implementado.

A seguir estão apresentadas medidas obtidas em ensaios realizados em 3 dias distintos, os quais tiveram medidas contínuas durante o período útil do dia sem ocorrência de problemas como excesso de cobertura do sol, falhas de firmware, falhas de acerto da posição do painel na estrutura, entre outros.

Embora a aquisição de dados tenha ocorrido a cada minuto, optou-se por exibir os dados de média de cada hora do dia, compreendidas entre as $5 \mathrm{~h}$ e as 17h. Todas as medidas foram executadas na cidade de Cotia-SP, em um local aberto e com poucos pontos de bloqueio dos raios solares durante o dia.

5.1.1. Dia 29/11/2014 - dia nublado e sem chuva

O dia 29/11/2014 foi um bom exemplar de dia nublado e sem chuva. Como se pode observar nos dados da Tabela 2, a irradiância esteve muito baixa durante todo o dia, o que levou a uma corrente gerada muito baixa. A tensão do painel ficou basicamente entre $11 \mathrm{~V}$ e $12 \mathrm{~V}$ devido à bateria que está conectada em curto com o painel. $O$ fato de o dia estar muito nublado impediu qualquer tentativa de rastreamento solar pelos fotodiodos, sendo que o sistema ficou sendo controlado pelo algoritmo SPA (Solar Position Algorithm) do NREL [19]. Por esse algoritmo, obteve-se os valores de azimute (coluna ângulo na Tabela 2) e de altitude. Observou-se que, neste ensaio, provavelmente teria sido mais indicado não realizar qualquer controle de 
posicionamento do painel, pois essa operação não aumentou o ganho de energia, mas acabou por gastar mais do que foi gerado. Uma melhoria no sistema de controle seria uma forma de detectar que a carga da bateria está diminuindo consistentemente e cessar o controle até que a situação retorne a um estado sustentável.

Como o sistema construído não possui apenas um eixo de rotação, o ângulo de Azimute foi utilizado para posicionar o painel solar entre o leste (-90 graus) até o oeste (+90 graus). Porém, como observado anteriormente, um problema de projeto mecânico do suporte do painel solar permite apenas 39,55 graus para um lado e 55,61 graus para o outro de excursão. Com isso, o sistema saturou o ângulo do painel nesses valores nos dois extremos.

A altitude calculada pelo algoritmo SPA [19] foi utilizada para realizar a estimação do melhor ângulo norte-sul do painel, o qual é ajustado manualmente. Como o experimento foi realizado no hemisfério sul, o painel deve ser posicionado apontando para o norte, e o ângulo foi determinado como sendo a média das altitudes calculadas para todos os horários entre as $10 \mathrm{~h}$ e as $15 \mathrm{~h}$, pois é o período considerado como o de maior captação de energia solar, em média. Esse valor médio de altitude resultou 68,97 graus, então o painel foi posicionado em 21,03 graus na direção norte (com sua normal fazendo o ângulo de 68,97 com o plano horizontal). 
Fazendo-se o cálculo do rendimento do sistema hora a hora - dividindo-se o valor da potência elétrica gerada pela potência de energia solar recebida para o painel de 350 por $305 \mathrm{~mm}$ - e calculando-se a média desse rendimento, obteve-se $4,22 \%$.

\begin{tabular}{|c|c|c|c|c|c|c|}
\hline Hora & Tensão $(\mathbf{V})$ & Corrente $(\mathbf{m A})$ & Irradiância $\left(\mathbf{W} / \mathbf{m}^{2}\right)$ & Umidade Rel. (\%) & Temperatura ( $\left.{ }^{\circ} \mathbf{C}\right)$ & Ângulo (graus) \\
\hline 5 & 11,15 & 6,33 & 15,58 & 81 & 18,6 & $-122,33$ \\
\hline 6 & 11,16 & 6,44 & 15,85 & 83 & 18,3 & $-115,21$ \\
\hline 7 & 11,16 & 6,35 & 15,63 & 80 & 18,6 & $-109,46$ \\
\hline 8 & 11,15 & 6,37 & 15,68 & 74 & 18,6 & $-104,59$ \\
\hline 9 & 11,11 & 6,31 & 15,54 & 75 & 18,6 & $-100,23$ \\
\hline 10 & 11,10 & 6,47 & 15,94 & 76 & $-96,01$ \\
\hline 11 & 11,09 & 7,02 & 17,29 & 73 & 20,2 & $-91,33$ \\
\hline 12 & 11,09 & 7,54 & 18,57 & 68 & 21,5 & $-83,65$ \\
\hline 13 & 11,08 & 8,19 & 20,16 & 62 & 23,5 & 25,43 \\
\hline 14 & 11,06 & 9,30 & 22,91 & 59 & 23,6 & 85,29 \\
\hline 15 & 11,09 & 10,24 & 25,23 & 58 & 23,9 & 92,11 \\
\hline 16 & 11,08 & 9,57 & 23,57 & 64 & 23,7 & 96,67 \\
\hline 17 & 11,09 & 10,20 & 25,11 & 64 & 23,9 & 100,89 \\
\hline
\end{tabular}

Tabela 2 - Resultados para o dia 29/11/2014

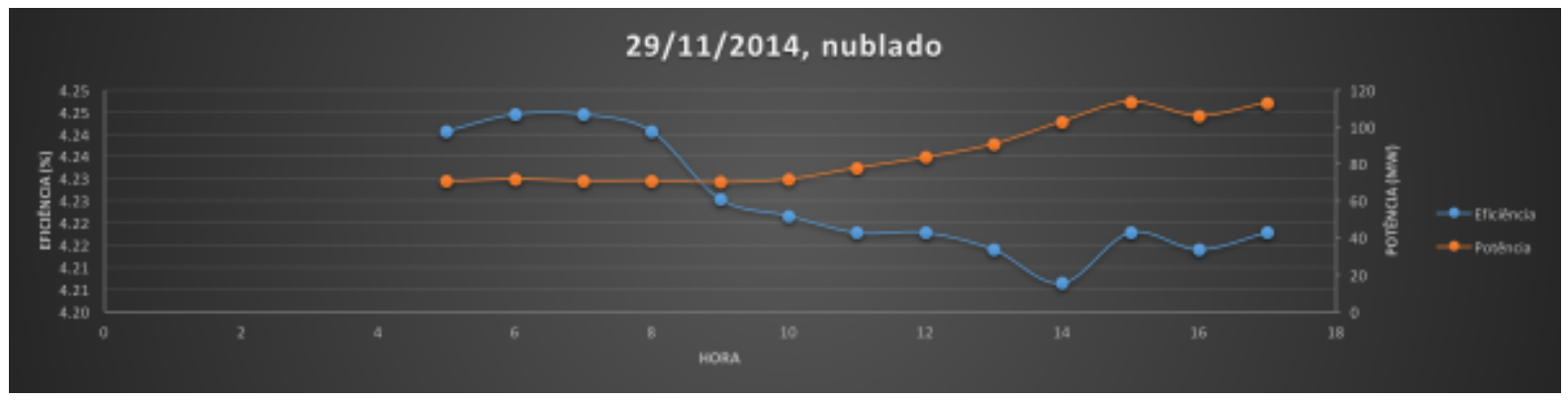

Figura 25 - Gráfico de eficiência e potência obtidos em cada hora do dia 29/11/2014

5.1.2. Dia 31/12/2014 - ensolarado, pouca cobertura de nuvens

O próximo dia escolhido para realizar um ensaio foi em 31/12/2014. Ao contrário do ensaio anterior, este exemplifica a operação do sistema em um 
dia bastante ensolarado, com pouca cobertura de nuvens. A irradiância e, consequentemente, a corrente gerada, se mostraram uma ordem de grandeza acima em comparação com o anterior. Os parâmetros de umidade relativa e temperatura não se mostraram suficientemente diferentes em relação ao ensaio anterior para ser possível tecer qualquer conclusão sobre a influência desses fatores sobre os resultados.

Neste dia foi possível obter dados mais estáveis dos fotodiodos, contudo a distância pequena dos mesmos na placa de sensores não foi suficiente para que eles apresentassem valores suficientemente diferentes entre si para inferir necessidades de mudança de ângulo do painel solar. Assim, em um projeto que se baseie neste trabalho, os fotodiodos do sistema devem possuir maior distância entre si, além de um atenuador de irradiação solar - como um filme plástico - a fim de se obter menos casos de saturação desses sensores. Assim, não foi possível realizar o rastreamento solar por sensores, baseando-se novamente no algoritmo SPA para tanto.

Foi possível observar nesse dia que o algoritmo de posicionamento SPA estava controlando satisfatoriamente o sistema, apontando o painel para a direção do sol. Isso pode ser observado também pela corrente que foi gerada nos horários de melhor aproveitamento de geração fotovoltaica, das $9 \mathrm{~h}$ às $15 \mathrm{~h}$ : o aumento da irradiação solar foi acompanhado de aumento na corrente gerada de forma aproximadamente proporcional. 


\begin{tabular}{|c|c|c|c|c|c|c|}
\hline Hora & Tensão $(\mathbf{V})$ & Corrente $(\mathbf{m A})$ & Irradiância $\left(\mathbf{W} / \mathbf{m}^{2}\right)$ & Umidade Rel. (\%) & Temperatura ( $\left.{ }^{\circ} \mathrm{C}\right)$ & Ângulo (graus) \\
\hline 5 & 11,12 & 0,00 & 0,00 & 60 & 22,6 & $-125,74$ \\
\hline 6 & 11,12 & 0,00 & 0,00 & 62 & 22,3 & $-118,22$ \\
\hline 7 & 11,15 & 17,01 & 29,69 & 63 & 22,2 & $-112,26$ \\
\hline 8 & 11,20 & 124,45 & 215,19 & 59 & 23,5 & $-107,33$ \\
\hline 9 & 11,29 & 257,86 & 445,00 & 60 & 23,7 & $-103,10$ \\
\hline 10 & 11,40 & 288,20 & 497,78 & 62 & 24,3 & $-99,29$ \\
\hline 11 & 11,52 & 428,56 & 738,89 & 55 & 26,2 & $-95,67$ \\
\hline 12 & 11,63 & 548,42 & 945,56 & 47 & 28 & $-91,74$ \\
\hline 13 & 11,71 & 571,60 & 1086,39 & 43 & 30,4 & $-78,61$ \\
\hline 14 & 11,79 & 572,97 & 1016,67 & 40 & 39,89 \\
\hline 15 & 11,83 & 368,54 & 636,39 & 41 & 30,5 & 94,35 \\
\hline 16 & 11,89 & 440,10 & 759,17 & 34 & 31,2 & 97,99 \\
\hline 17 & 11,94 & 360,13 & 624,44 & 37 & 31 & 101,70 \\
\hline
\end{tabular}

Tabela 3 - Resultados para o dia 31/12/2014

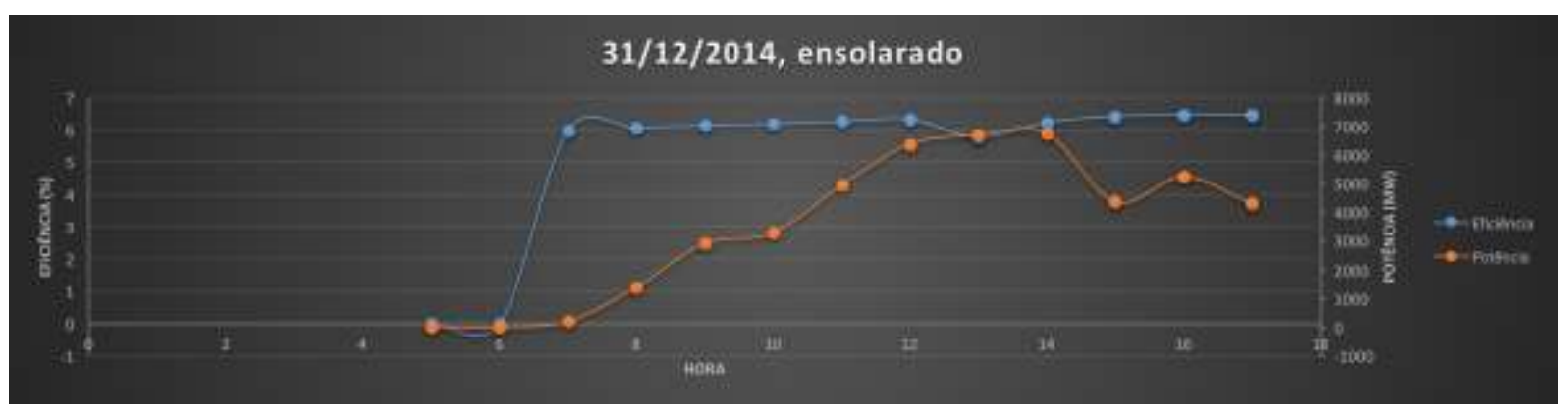

Figura 26 - Gráfico de eficiência e potência obtidos em cada hora do dia 31/12/2014

Foi possível observar nesse dia que o algoritmo de posicionamento SPA estava controlando satisfatoriamente o sistema, apontando o painel para a direção do sol. Isso pode ser observado também pela corrente que foi gerada nos horários de melhor aproveitamento de geração fotovoltaica, das $9 \mathrm{~h}$ às 
$15 \mathrm{~h}$ : o aumento da irradiação solar foi acompanhado de aumento na corrente gerada de forma aproximadamente proporcional.

Este ensaio obteve um rendimento médio de $6,21 \%$.

Assim como foi feito no ensaio anterior, a média das altitudes calculadas pelo algoritmo SPA foi utilizado como o ângulo manualmente acertado no sistema na direção norte-sul. Este ângulo foi de 68,59 graus, com o painel sendo ajustado manualmente em um ângulo de 21,41 graus.

5.1.3. Dia 30/01/2015 - cobertura parcial de nuvens

O terceiro ensaio selecionado foi no dia 30/01/2015. Este ensaio pode ser considerado como o que teve um resultado intermediário em comparação com os dois últimos, com uma geração de energia mais modesta, porém considerável.

Devido aos mesmos motivos do ensaio anterior, não foi possível controlar o sistema baseado no sinal dos fotodiodos. Mesmo com a menor irradiância, esses últimos continuaram sendo esporadicamente saturados, além de não apresentarem valores diferenciais entre si para poder inferir a próxima posição do painel solar.

Este ensaio obteve um rendimento médio de 6,12 \%.O algoritmo SPA gerou como média das altitudes o valor de 66,2 graus, de forma que se inclinou manualmente o painel para 23,8 graus. $O$ algoritmo mais uma vez se mostrou satisfatório no posicionamento do sistema. 


\begin{tabular}{|c|c|c|c|c|c|c|}
\hline Hora & Tensão (V) & Corrente (mA) & Irradiância $\left(\mathrm{W} / \mathrm{m}^{2}\right)$ & Umidade Rel. (\%) & Temperatura $\left({ }^{\circ} \mathrm{C}\right)$ & Ângulo (graus) \\
\hline 5 & 11,01 & 0,00 & 0,00 & 68 & 22.5 & $-122,63$ \\
\hline 6 & 11,01 & 0,00 & 0,00 & 73 & 21.7 & $-114,65$ \\
\hline 7 & 11,02 & 1,67 & 2,88 & 75 & 21.6 & $-108,26$ \\
\hline 8 & 11,05 & 45,05 & 77,67 & 75 & 22.1 & $-102,81$ \\
\hline 9 & 11,09 & 142,79 & 246,19 & 71 & 23.1 & $-97,79$ \\
\hline 10 & 11.15 & 241,99 & 417,22 & 68 & 23.9 & $-92,67$ \\
\hline 11 & 11,22 & 270,02 & 465,56 & 64 & 25.4 & $-86,50$ \\
\hline 12 & 11,26 & 283,72 & 489,17 & 63 & 24.9 & $-76,33$ \\
\hline 13 & 11,31 & 307,56 & 530,28 & 63 & 25.6 & $-40,16$ \\
\hline 14 & 11,40 & 309,98 & 534,44 & 61 & 26.4 & 58,85 \\
\hline 15 & 11,45 & 371,36 & 640,28 & 61 & 26.0 & 80,24 \\
\hline 16 & 11,48 & 238,44 & 411,11 & 64 & 25.2 & 88,52 \\
\hline 17 & 11,52 & 101,84 & 175,58 & 71 & 23.8 & 94,20 \\
\hline
\end{tabular}

Tabela 4 - Resultados para o dia 30/01/2015

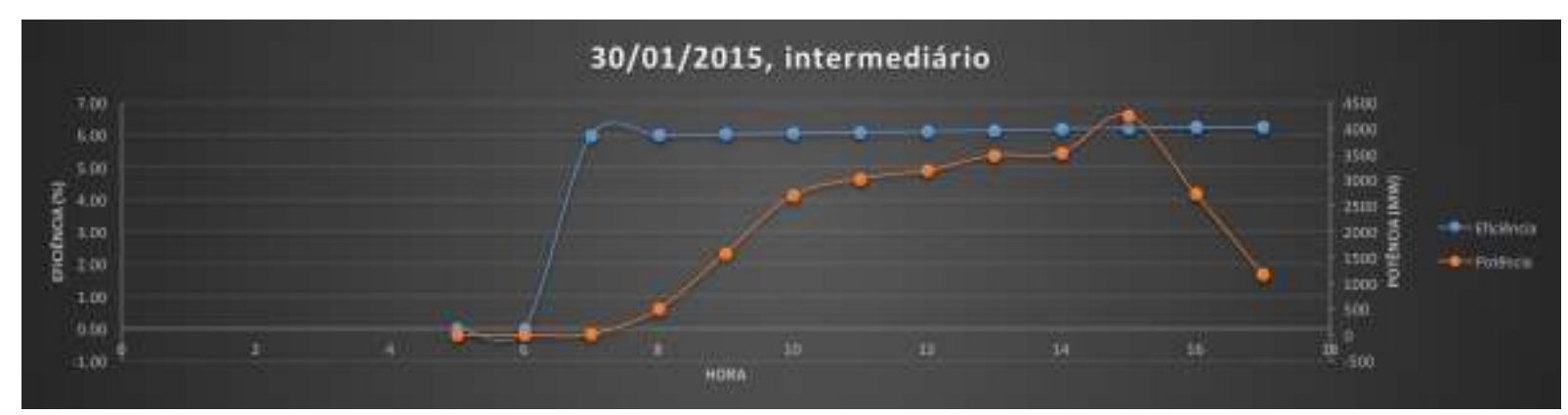

Figura 27 - Gráfico de eficiência e potência obtidos em cada hora do dia 30/01/2015

5.1.4. Dia 31/01/2015 - cobertura parcial de nuvens, sem rastreamento

Por fim, realizou-se mais um ensaio, agora sem qualquer tipo de rastreamento, no dia 31/01/2015. Esse dia se mostrou bastante simular com o dia anterior, com cobertura parcial de nuvens, sem a ocorrência de chuva.

O objetivo dessa medida é se obter uma comparação de geração de energia entre os ensaios com rastreamento e o ensaio estático. Para isso, posicionou- 
se o painel manualmente com um ângulo de 23 graus para o norte na direção norte-sul e 0 grau de inclinação no sentido Leste-Oeste, posição na qual geralmente o sistema de rastreamento do sol posicionaria o painel próximo do meio-dia. Os resultados estão a seguir.

Após o ensaio, constatou-se o rendimento médio de 4,4\%. Considerando que este ensaio possui valores de irradiação da mesma ordem de grandeza do anterior, pode-se concluir que o processo de rastreamento está de fato beneficiando a geração de energia.

\begin{tabular}{|c|c|c|c|c|c|c|}
\hline Hora & Tensão $(\mathbf{V})$ & Corrente $(\mathbf{m A})$ & Irradiância $\left(\mathbf{W} / \mathbf{m}^{2}\right)$ & Umidade Rel. (\%) & Temperatura ${ }^{\circ} \mathbf{C}$ ) & Ângulo (graus) \\
\hline 5 & 11,30 & 0,00 & 0,00 & 90 & 19.3 & 0,00 \\
\hline 6 & 11,30 & 0,00 & 0,00 & 88 & 19.8 & 0,00 \\
\hline 7 & 11,30 & 0,44 & 1,52 & 86 & 20.1 & 0,00 \\
\hline 8 & 11,31 & 9,61 & 30,11 & 85 & 20.5 & 0,00 \\
\hline 9 & 11,32 & 40,62 & 116,72 & 81 & 21.3 & 0,00 \\
\hline 10 & 11,32 & 70,64 & 174,00 & 83 & 21.0 & 0,00 \\
\hline 11 & 11,33 & 137,95 & 264,28 & 77 & 22.8 & 0,00 \\
\hline 12 & 11,35 & 144,28 & 248,75 & 74 & 23.1 & 0,00 \\
\hline 13 & 11,36 & 113,33 & 195,39 & 73 & 23.3 & 0,00 \\
\hline 15 & 11,38 & 105,71 & 227,83 & 70 & 23.7 & 0,00 \\
\hline 16 & 11,38 & 84,40 & 207,89 & 70 & 23.8 & 0,00 \\
\hline 17 & 11,38 & 51,62 & 148,33 & 70 & 23.7 & 0,00 \\
\hline
\end{tabular}

Tabela 5 - Resultados para o dia 31/01/2015

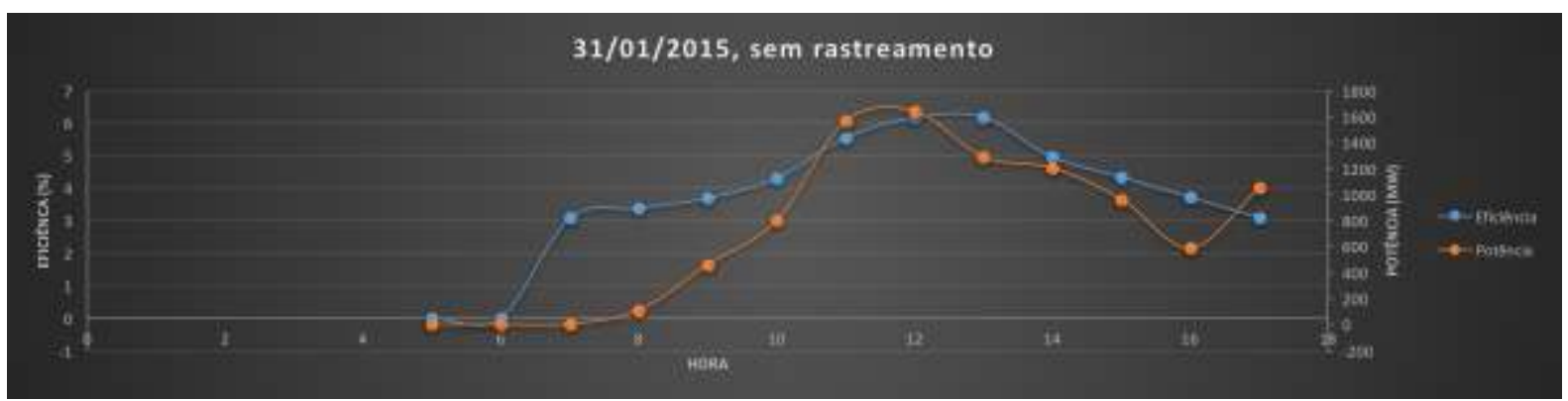

Figura 28 - Gráfico de eficiência e potência obtidos em cada hora do dia 31/01/2015 


\section{Discussão e Conclusões}

O projeto do sistema de rastreamento solar baseado em um sistema embarcado mostrou que é possível aumentar o ganho de energia elétrica fotovoltaica. Observou-se, contudo, que a falta de detecção por parte do sistema de que determinadas condições são desfavoráveis ao rastreamento solar - como um dia muito nublado, por exemplo - pode levar a uma perda de energia por excesso de tentativas de rastreamento solar, com rendimento muito baixo dessa operação.

Percebeu-se que em condições menos desfavoráveis, o rendimento do sistema foi satisfatório. Observa-se, no entanto, que a execução das melhorias apontadas no início do capítulo 5 tornaria o sistema ainda mais eficiente e confiável.

O fato de o projeto dos fotodiodos não ter funcionado para o controle do rastreamento solar impediu que parte dos experimentos previamente planejados fosse executada. Contudo, o controle pelo algoritmo SPA tornou possível observar o ganho de energia elétrica gerada pelo sistema.

Foi observado que o passo ótimo de atualização de posição do painel foi de 5 graus, ou seja, passou-se a deixar de aumentar a eficiência do sistema quando a necessidade mínima de alteração de posição passou para valores maiores do que 5 graus. Observa-se, no entanto, que esse valor é bem específico 
deste sistema, considerando que todos os parâmetros mecânicos como pesos, atritos e folgas influem nessa determinação. Um sistema de maior escala deverá passar pelo mesmo processo e determinar o seu valor ótimo.

Por fim, um fator limitante à aplicação do método exposto neste trabalho é o custo do projeto. Algumas decisões que foram tomadas com o objetivo de se atingir a maior performance possível, como o uso de servomotor ao invés de motor de passo, fonte de alimentação chaveada na placa de controle, conectores destacáveis, entre outros, encareceram o projeto. Uma aplicação de mercado precisará realizar uma remodelagem de certas partes do sistema para que ele se torne economicamente viável. 


\section{Previsão de continuação da pesquisa}

O primeiro passo para a continuação dessa pesquisa seria a correção dos problemas identificados no item 5 .

Uma vez queo sistema possua a capacidade de medir a carga da bateria, saúde da mesma, quantidade de energia gasta pelo sistema de rastreamento, bem como seja capaz de realizar o rastreamento por sensores e/ou algoritmos, a pesquisa poderia ser estendida para observar o ganho de energia elétrica em um arranjo de diversos painéis solares com capacidade de rastreamento (escravos) - e, portanto, com capacidade de acionamento -, porém, em apenas alguns haveria a possibilidade de sensoriamento e processamento (mestres).

O objetivo com isso seria obter uma solução viável economicamente, com mínimo de desperdício de energia, que processasse por área a necessidade de atualização de rastreamento e comando remoto dos demais painéis escravos.

Essa solução poderia ser replicada para grandes áreas com mais painéis, de forma a se obter um considerável ganho de energia. 


\section{Referências}

[1] F. C. Treble, "Solar Cells," in IEE Proceedings, Novembro 1980.

[2] A. Kassem and M. Hamad, "A Microcontroller-Based Multi-Function Solar Tracking System," Department of Electrical and computer and communication Engineering, Notre Dame University Louaize, Zouk Mosbeh, 2011.

[3] M. A. Martínez, J. M. Andújar e J. M. Enrique, "A New and Inexpensive Pyranometer for the Visible Spectral Range," Sensors, pp. 4615-4624, 12 Junho 2009.

[4] H. Mousazadeh, A. Keyhani, A. Javadi, H. Mobli, K. Abrinia and A. Sharifi, "A review of principle and sun-tracking methods for maximizing solar systems output," Renewable and Sustainable Energy Reviews, pp. 18001818, 20 Janeiro 2009.

[5] T. A. Khan, S. Alam, R. Rahman and S. Tanzil, "Design and Construction of an Automatic Solar Tracking System," in 6th International Conference on Electrical and Computer Engineering, Dhaka, 2010.

[6] D. S. Karanjkar, A. Kumar, S. Chatterji e S. L. Shimi, "An Improved Current 
Feedback Based Maximum Power Point Tracking Controller for Solar Photo- Voltaic System," em International Conference on Microelectronics, Communication and Renewable Energy (ICMiCR-2013), Chandigarh, 2013.

[7] Y. Wang e J. Song, "Design of a Digital Solar Panel Automatic Tracking Controller for Photovoltaic Generation System," Suzhou Vocational University, Suzhou, 2012.

[8] F. B. Zia, K. M. Salim, N. B. Yousuf, R. Haider e R. Alam, "Design and Implementation of a Single Phase Grid Tie Photo Voltaic Inverter," School of Engineering and Computer Science, Independent University Bangladesh, Dhaka.

[9] A. H. Yamin, M. N. Ibrahim, M. Idroas e A. R. Zin, "Embedded Solar Tracking Instrumentation System," em IEEE 7th International Power Engineering and Optimization Conference, Langkawi, 2013.

[10] P. J. Hession and W. J. Bonwick, "Experience with a Sun Tracker," Solar Energy Vol. 32 No. 1, pp. 3-11, 10 março 1983.

[11] C. A. Balafas, M. D. Athanassopoulou, T. Argyropoulos, P. Skafidas and C. T. Dervos, "Effect of the Diffuse Solar Radiation on Photovoltaic Inverter 
Output," in 15th IEEE Mediterranean Electrotechnical Conference, Valeta, Malta, 2010.

[12] E. Hossain, R. Muhida and A. Ali, "Efficiency Improvement of Solar Cell Using Compound Parabolic Concentrator and Sun Tracking System," in IEEE Electrical Power \& Energy Conference, Vancouver, 2008.

[13] N. Barsoum, "Implementation of a Prototype for a Traditional Solar Tracking System," em Third UKSim European Symposium on Computer Modeling and Simulation, Atenas, 2009.

[14] S. Armstrong e W. G. Hurley, "Investigating the Effectiveness of Maximum Power Point Tracking for a Solar System," pp. 204-209, 2005.

[15] A. Argeseanu, E. Ritchie and K. Leban, "New Low Cost Structure for Dual Axis Mount Solar Tracking System Using Adaptive Solar Sensor," in 12th International Conference on Optimization of Electrical and Electronic Equipment, Brasov, 2010.

[16] I. T. Salamoni e R. Ruther, "O Potencial Brasileiro de Geração Solar Fotovoltaica Conectada à Rede Elétrica: Análise de Paridade de Rede," em IX Encontro Nacional e V Latino Americano de Conforto no Ambiente 
Construído, Ouro Preto, 2007.

[17] X. Zhang, X. Li e K. Lu, "Research on an Intelligent Solar Tracking System Based on LPC2131," em Network Infrastructure and Digital Content (ICNIDC), Beijing, China, 2012.

[18] A. S. Sedra e K. C. Smith, Microeletrônica, 4a ed., P. Hall, Ed., 2000.

[19] I. R. e. A. Andreas, "Solar Position Algorithm for Solar Radiation Applications," Golden, Colorado, 2008. 


\section{Anexos}

\subsection{Anexo 1 - Circuito principal da placa controladora}

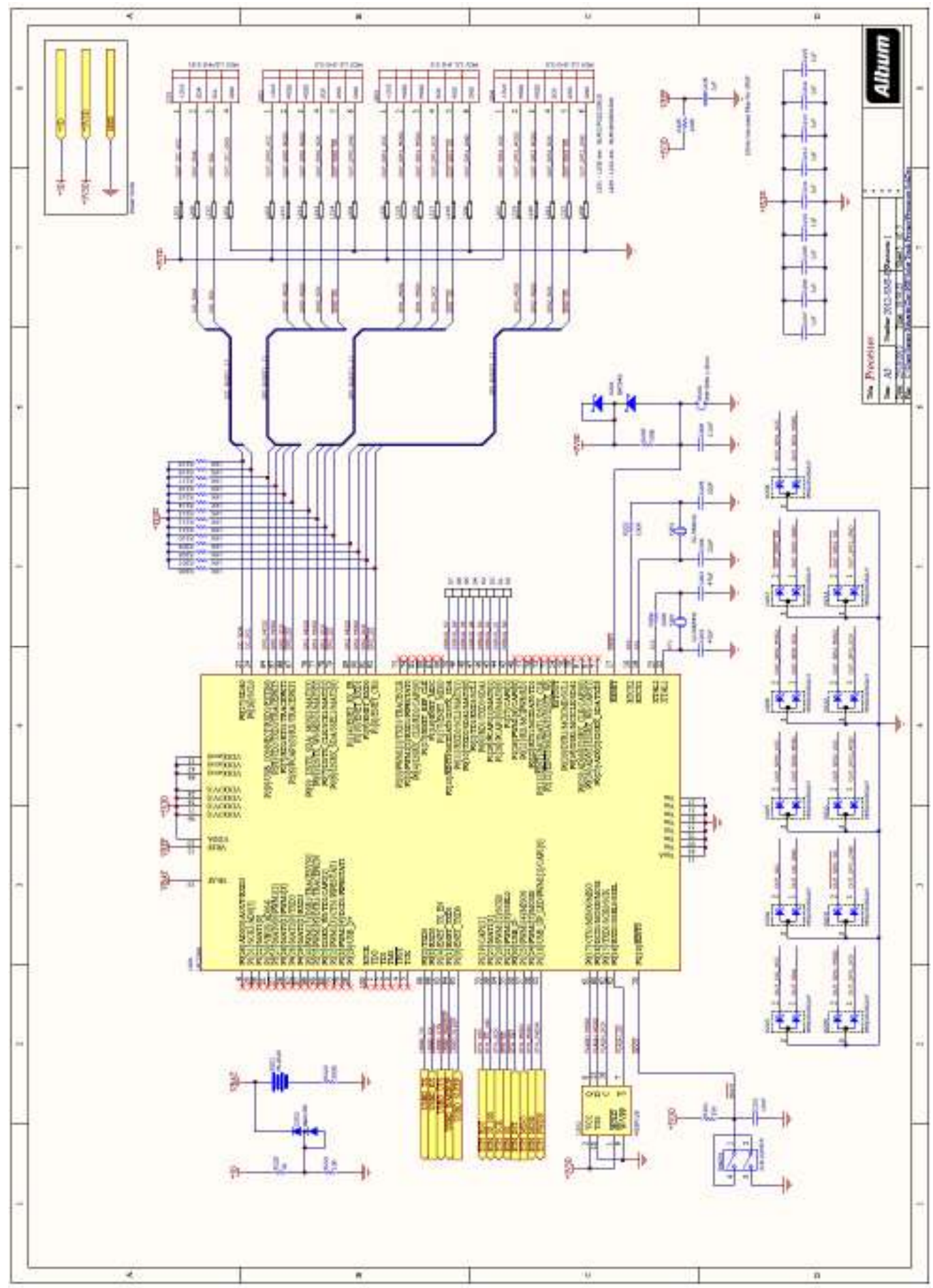


9.1.1. Camada Top da placa de circuito impresso

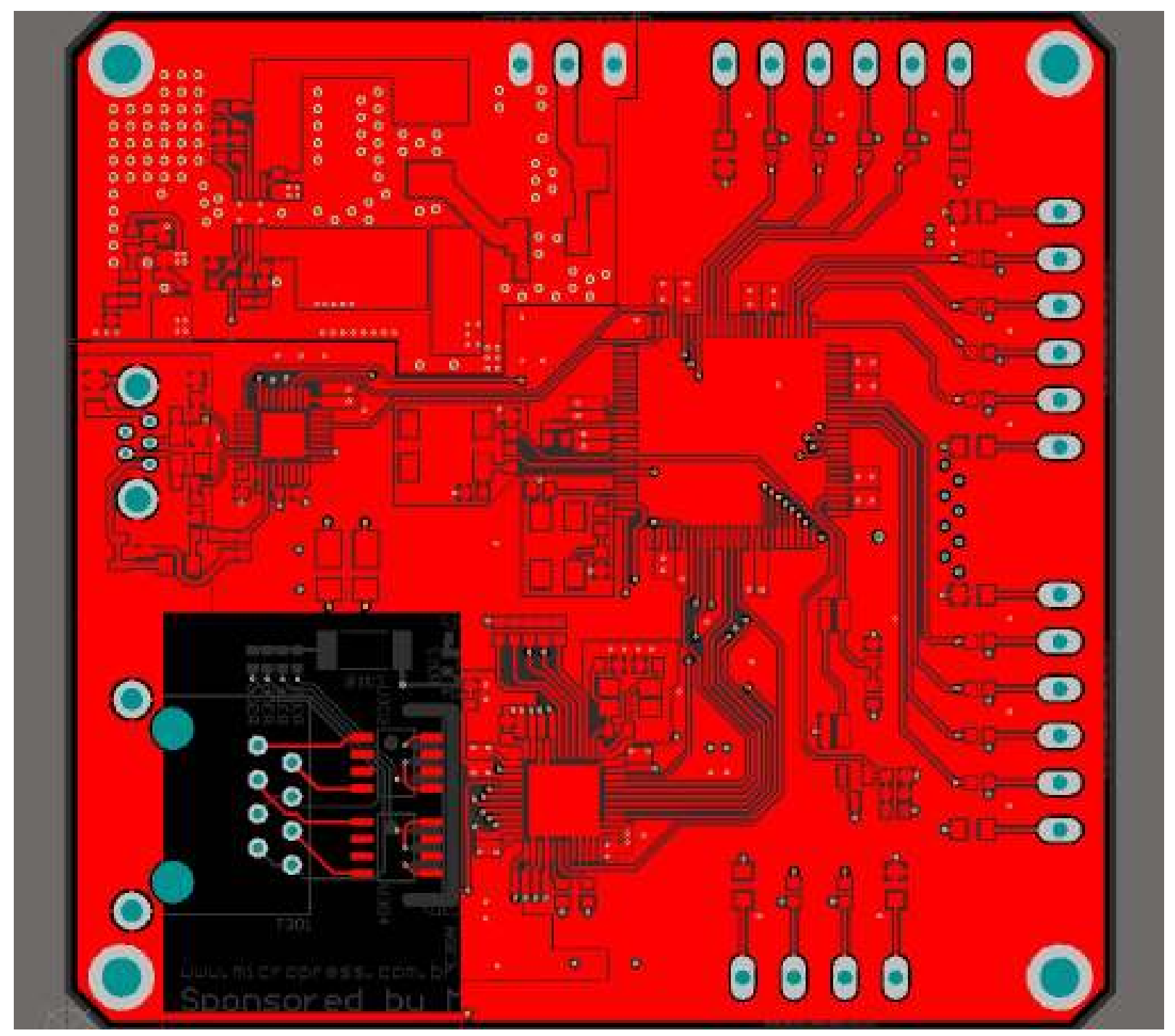


9.1.2. Camada Bottom da placa de circuito impresso

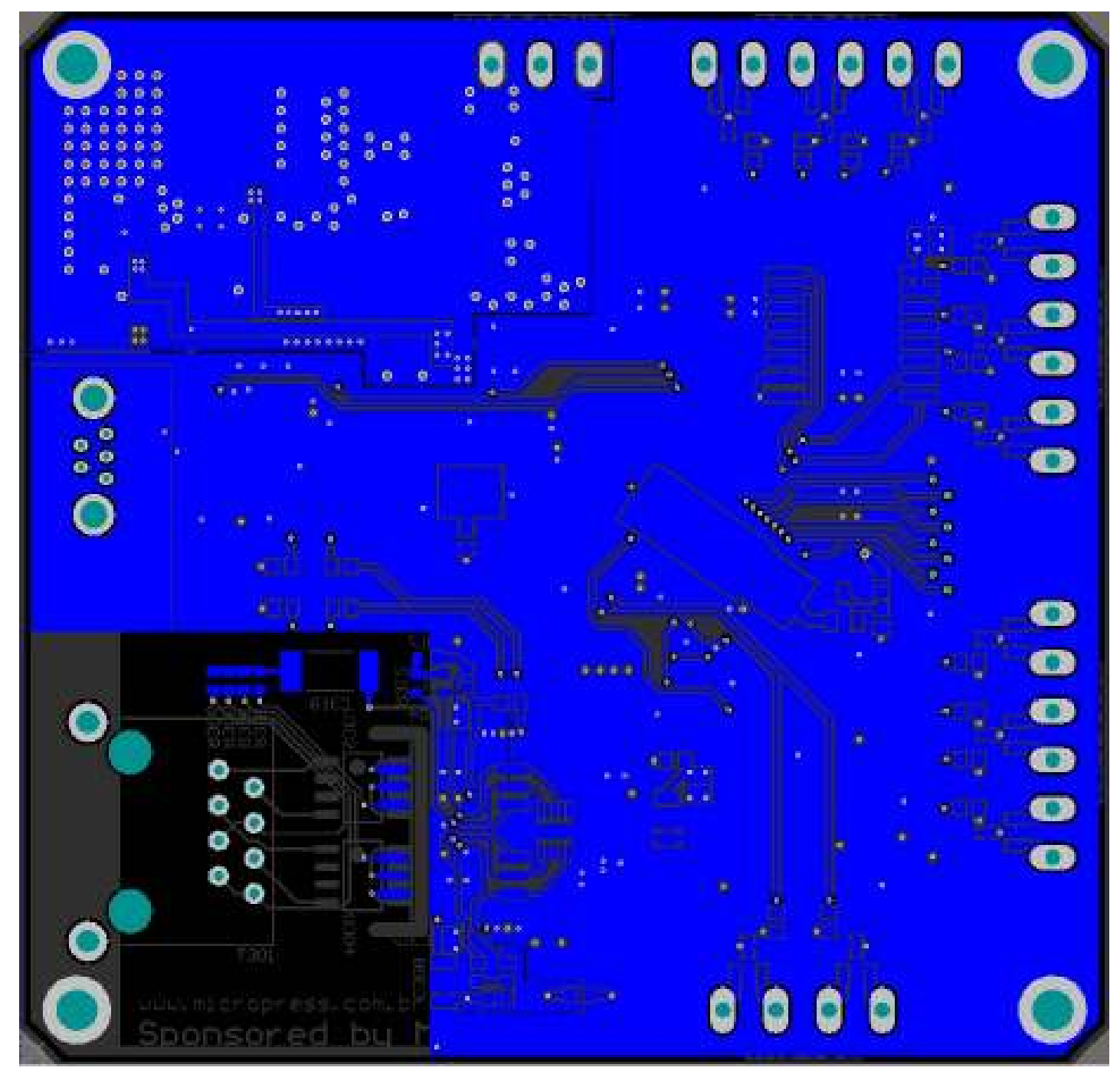




\subsubsection{Camada VCC da placa de circuito impresso}

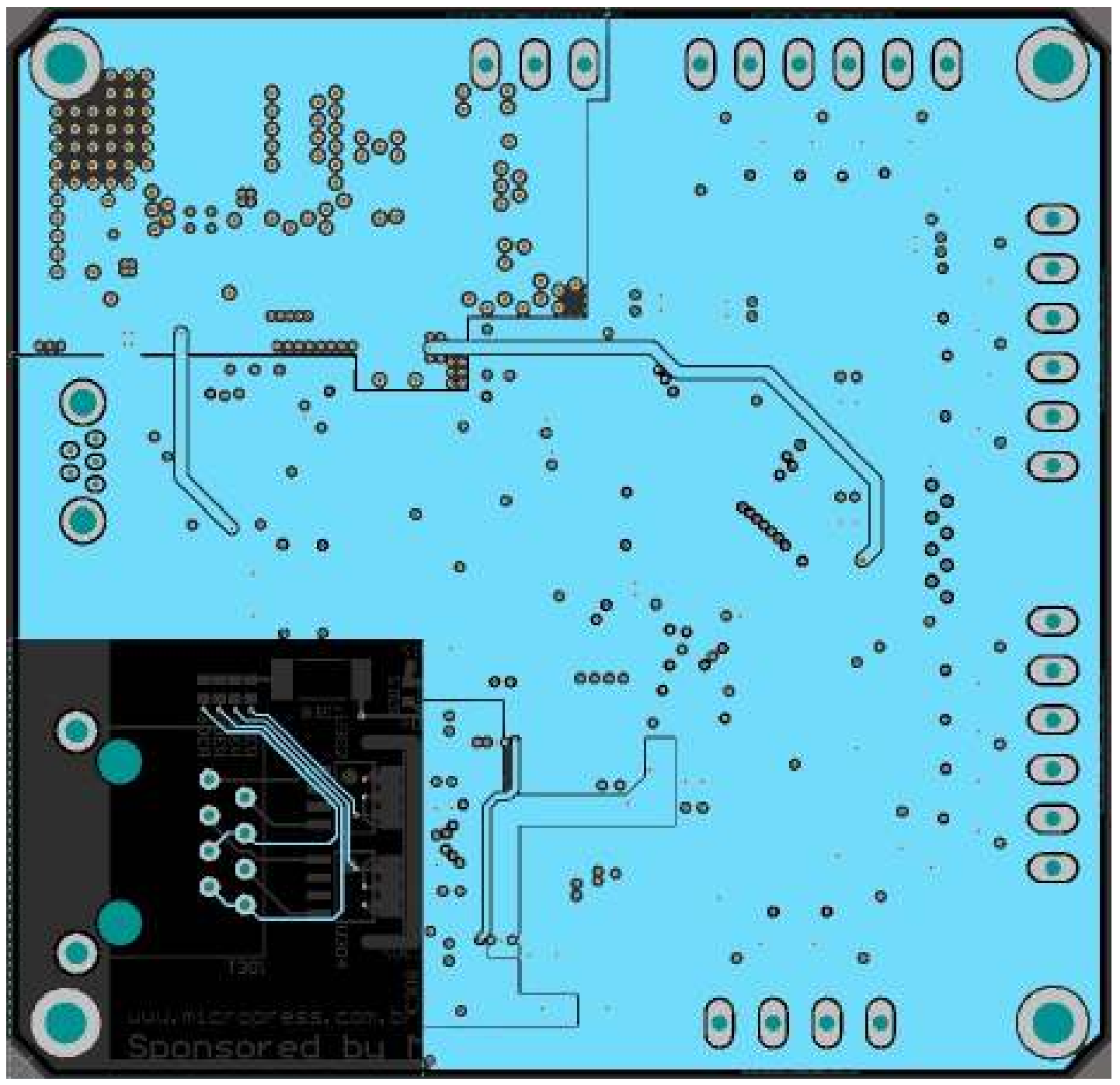


9.1.4. Camada GND da placa de circuito impresso

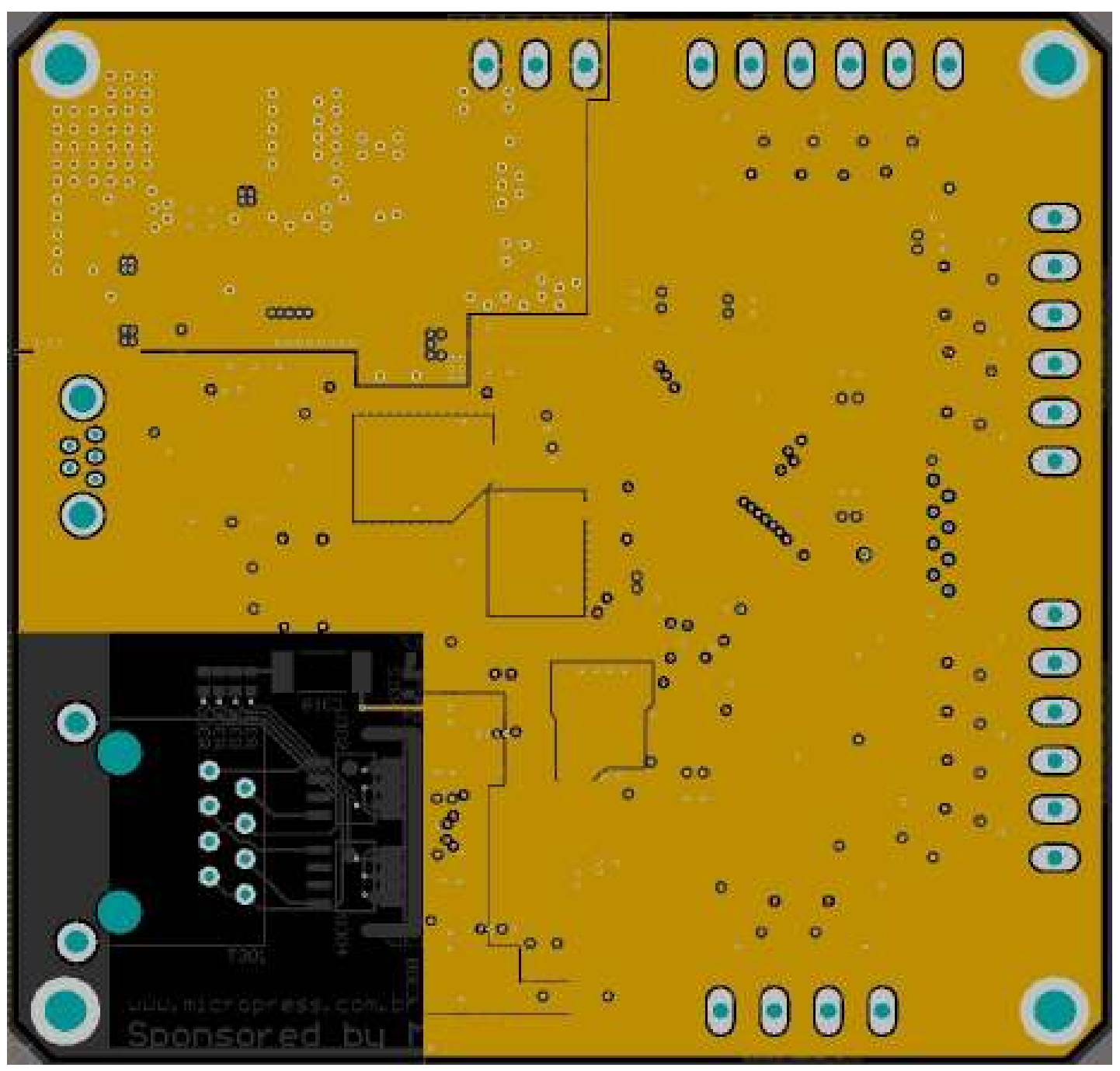




\subsection{Anexo 2 - Circuito da placa de sensores}

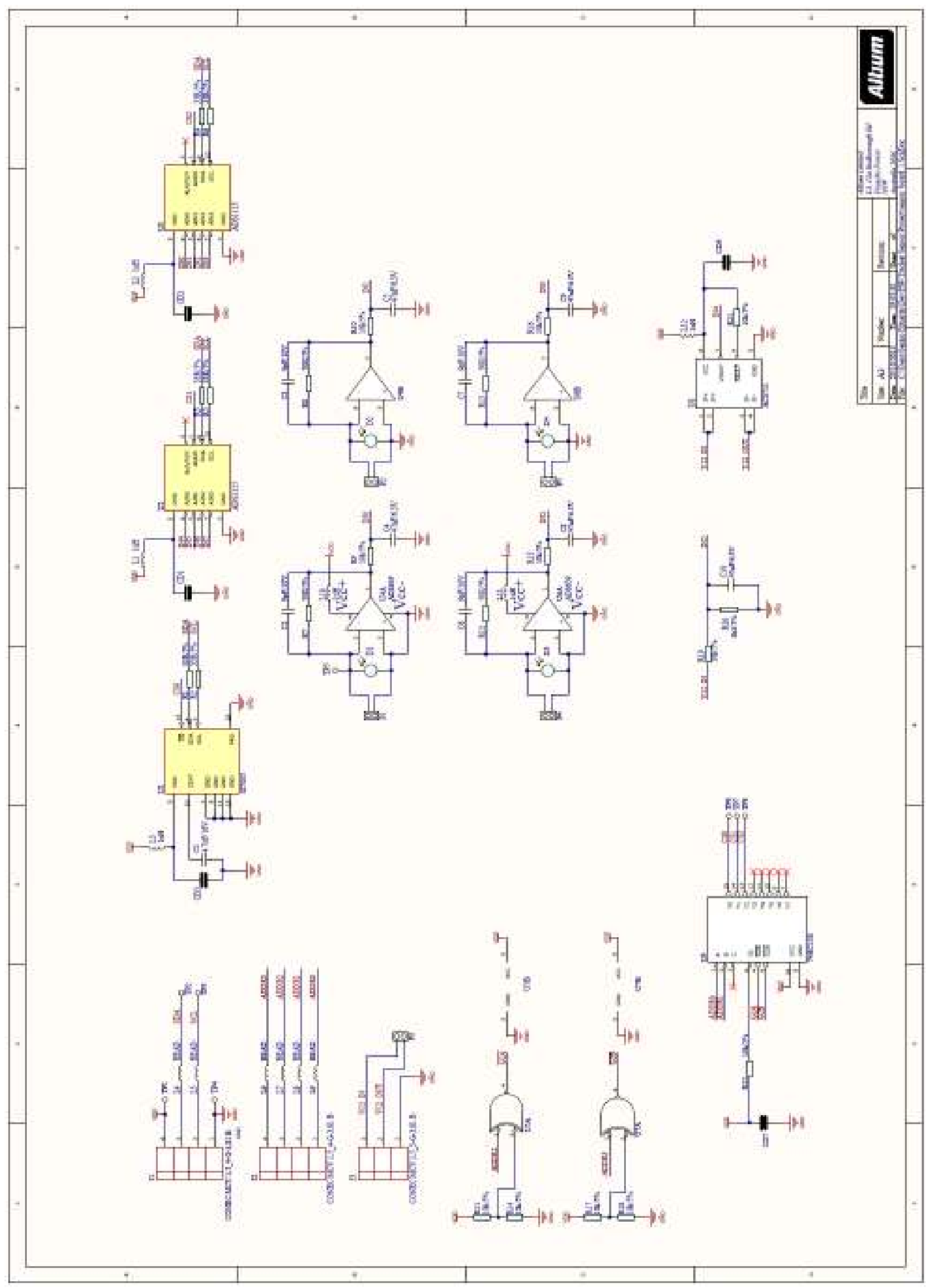


9.3. Anexo 3 - Diagrama de distribuição do sistema

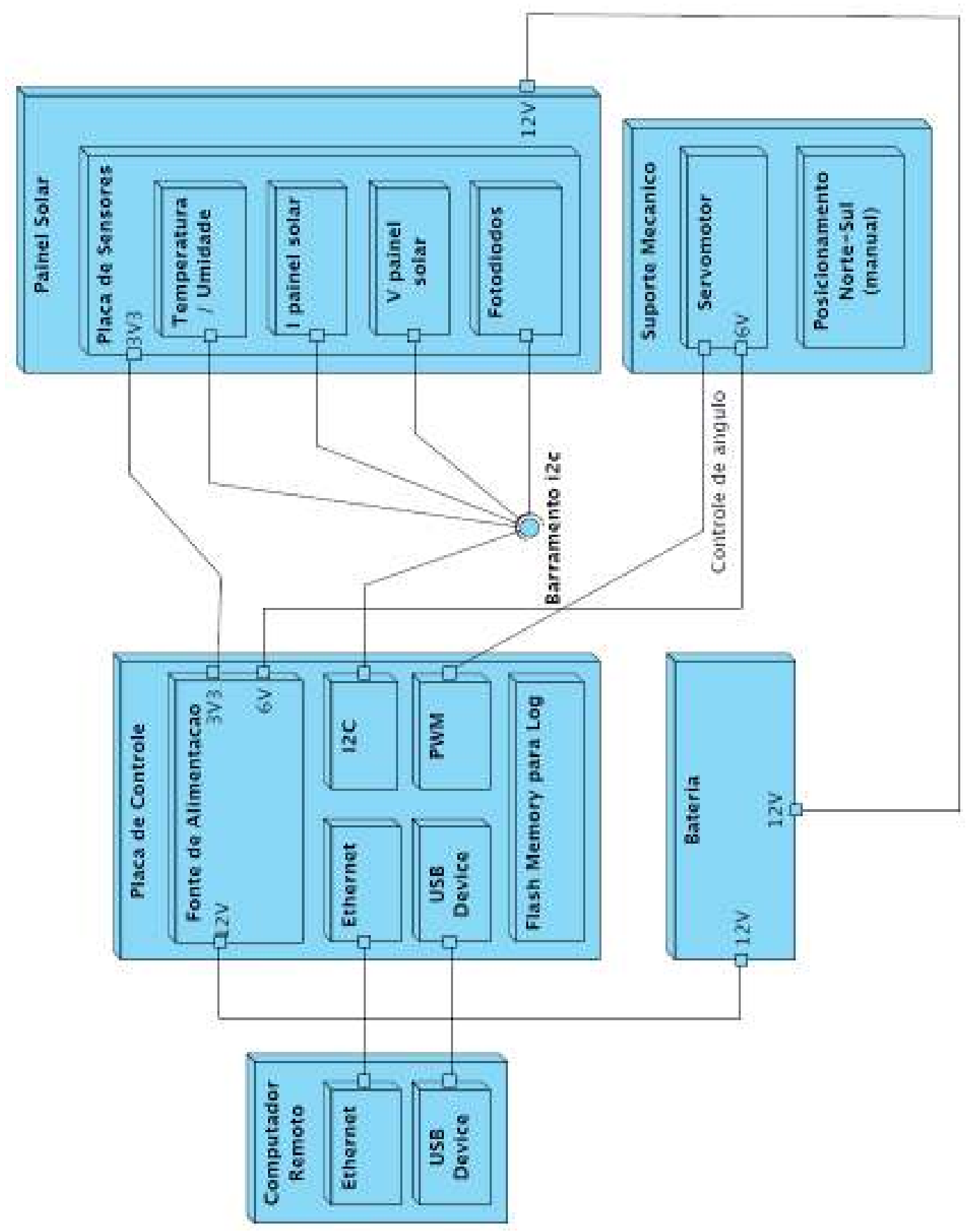

